\title{
Confluência do Capital Social, Empoderamento e Governança Ambiental na Sadia Qualidade de Vida em Comunidades Rurais no Ceará ${ }^{1}$
}

\author{
Magda Cristina de Sousa², Patrícia Verônica P. S. Lima ${ }^{3}$, \\ Ahmad Saeed Khan ${ }^{4}$ e Leonardo Andrade Rocha ${ }^{5}$
}

Resumo: A compreensão da forma como capital social, empoderamento e governança ambiental se relacionam em escala local pode fortalecer o papel do poder público e de instituições privadas na implementação de estratégias de promoção da qualidade de vida. Nessa perspectiva, o objetivo deste estudo é analisar a confluência do capital social, empoderamento e governança ambiental para a sadia qualidade de vida, em comunidades rurais, no Ceará. Para tanto, foram utilizados dados primários obtidos junto a representantes das comunidades. A operacionalização dos conceitos analisados foi realizada por meio da construção de índices agregados. Como principal método de análise foi estimado um modelo de equações estruturais. Os resultados mais relevantes mostraram que o capital social e o empoderamento se relacionam entre si na promoção da sadia qualidade de vida nas comunidades estudadas, enquanto a governança ambiental não consegue promover mudanças nesse sentido. Ficou evidente a importância da participação da comunidade no desenvolvimento/envolvimento melhorando, assim, o acesso a direitos sociais com a participação responsável e solidária para alcançar a sadia qualidade de vida, em um meio ambiente com equilíbrio ecológico, às presentes e futuras gerações.

Palavras-chaves: direitos sociais fundamentais, gestão compartilhada, desenvolvimento integrado.

Abstract: The understanding of how social capital, empowerment and environmental governance relate in the local level can strengthen the role of public power and private institutions in implementing strategies to promote quality of life. In this perspective the objective of this study is to analyse the

1. Data de submissão: 19 de março de 2016. Data de aceite: 21 de julho de 2017.

2. Universidade Federal Rural do Semiárido (Ufersa). Mossoró, Rio Grande do Norte, Brasil. E-mail: mzdsousa@hotmail.com

3. Universidade Federal do Ceará. Ceará, Brasil. E-mail: pvpslima@gmail.com

4. Universidade Federal do Ceará. Ceará, Brasil. E-mail: saeed@ufc.br

5. Universidade Federal Rural do Semiárido (Ufersa). Mossoró, Rio Grande do Norte, Brasil. E-mail: leonardoandrocha@yahoo.com.br 
confluence of social capital, empowerment and environmental governance for the healthy quality of life in rural communities in Ceará, Brazil. For this, primary data obtained from community representatives were used. The operationalization of the analysed concepts was accomplished through the construction of aggregate indexes. As the main method of analysis, a structural equation model was estimated. The most relevant results showed that social capital and empowerment are related to each other in promoting healthy quality of life in the communities studied, while environmental governance cannot promote change in this sense. The importance of community participation in development / involvement was evident, thus improving access to social rights with responsible and supportive participation in order to achieve the healthy quality of life in an ecologically balanced environment for present and future generations.

Key-words: fundamental social rights, shared management, integrated development.

Classificação JEL: I31, R58, O13.

DOI: http://dx.doi.org/10.1590/1234-56781806-94790550406

\section{Introdução}

As várias dimensões em que se apresenta o desenvolvimento econômico e social, seja global, regional ou local, têm levado à reflexão a partir de interesses interdisciplinares e transdisciplinares em torno dos conceitos de capital social, empoderamento, governança ambiental e sadia qualidade de vida nos mais diversos campos de atuação das ciências e disciplinas, sobretudo nas áreas das humanas e sociais. Utiliza-se o termo "sadia qualidade de vida", pois é a forma como encontra-se inserida no texto do artigo 225, da Constituição Federal de 1988 (CF/1988), ao se referir ao papel do poder público e da coletividade na defesa do meio ambiente: "Todos têm direito ao meio ambiente ecologicamente equilibrado, bem de uso comum do povo e essencial à sadia qualidade de vida, impondo-se ao Poder Público e à coletividade o dever de defendê-lo e preservá-lo para as presentes e futuras gerações" (grifo nosso).

Para Fiorillo (2005), a sadia qualidade de vida, na perspectiva do citado artigo, só será plenamente possível, concomitante à presença do artigo $5^{\mathbf{0}}$ da CF/1988 que estabelece que "todos são iguais perante a lei, sem distinção de qualquer natureza, garantindo-se aos brasileiros e aos estrangeiros residentes no País a inviolabilidade do direito à vida, à liberdade, à igualdade, à segurança e à propriedade", complementado com o artigo $1^{\circ}$, inciso III, que trata da dignidade da pessoa humana, fundamentado pelo acesso aos indicadores que compõem os direitos sociais, elencados no artigo 60, da CF/1988, que determina que "são direitos sociais fundamentais a educação, a saúde, a alimentação, o trabalho, a moradia, o lazer, a segurança, a previdência social, a proteção à maternidade e à infância, a assistência aos desamparados na forma desta Constituição" (Redação dada pela Emenda Constitucional, no 064, 2010).

Em um momento no qual as preocupações ambientais perpassam pelos mais diferentes escopos do desenvolvimento, surgem como conceitos relevantes e indissociáveis a confiança, a reciprocidade e a solidariedade. Como coloca Granovetter (1985), a maioria dos comportamentos está integrada em redes de relações interpessoais que solidificam as regras de conduta e de reciprocidade. A interação social torna possível a solução de dilemas de ação coletiva. Sen (1999) argumenta que se a pessoa vê as ações em termos de estratégia social, notando os respectivos objetivos de outras pessoas em posição semelhante à dela, seguir a estratégia cooperativa é pertinente. Isso motiva as pessoas a influir com confiança em situações em que, agindo de outra forma não se teria o engajamento cívico. Para Putnam (2003) a confiança lubrifica a vida social.

Essa configuração reforça a necessidade de reorganização estrutural do Estado democrático de direito no que se refere à aproximação das instituições de direito público e privado, a sociedade civil organizada e as organizações não governamentais (ONGs) e terceiro setor. Nesse sentido, tornam-se imprescindíveis o fortalecimento e a legitimação da participação de todos no exercício do Poder-dever compartilhado, com vistas a alcançar qualidade de vida, em um meio ambiente ecologicamente equilibrado. Tal cenário, por sua vez, 
requer a presença de capital social, empoderamento e uma boa governança ambiental.

A inter-relação entre esses conceitos surge como especialmente relevante em comunidades rurais, diante de mudanças recentes como novas formas de comunicação entre atores (ASHLEY e MAXWELL, 2001) e transformações institucionais (MACKINNON, 2007). Dadas as novas e diferentes relações rurais espera-se uma redefinição e reinterpretação de conceitos teóricos, que ajudem a entender essa nova dinâmica rural (VASILEVSKA, 2010). A compreensão da forma como capital social, empoderamento e governança ambiental se relacionam em escala local pode fortalecer o papel do poder público e de instituições privadas na implementação de estratégias de desenvolvimento rural. Trata-se de um novo olhar para as demandas rurais na realidade contemporânea (DE JANVRY e SADOULET, 2002; UMANS e ARCE, 2014), com vistas a reduzir problemas como a queda da qualidade de vida no campo e o aumento da pobreza ressaltados por Vasilevska (2010). Nesse sentido, o objetivo do artigo é analisar a confluência do capital social, empoderamento e governança ambiental na sadia qualidade de vida nas comunidades dentro e circunvizinhas do Polo de Desenvolvimento Integrado Tabuleiro de Russas, na microrregião do Baixo Jaguaribe, no Ceará.

Para tanto, se adota como fundamentação teórica o conceito de capital social de Bourdieu (1980), constituído pelo conjunto de recursos materiais e potenciais que ligam os indivíduos à rede de relações mais ou menos duráveis de conhecimento e reconhecimento. O capital social de Coleman (1990), como consequência natural de indivíduos que se relacionam em atividades que favorecem a socialização e, ainda, o de Putnam (1997), que aponta os valores éticos, a capacidade associativa, o nível de confiança, entre outros, como fonte de capital social.

Também são trabalhados os conceitos de empoderamento (empowerment) psicológico, social e político de Friedman (1992); Schiavo e Moreira (2005); Rich et al. (1995); Baquero e Baquero (2007) e Wallerstein e Bernstein (1994) e de governança ambiental, amparado na Constituição Federal e na legislação infraconstitucional, nas instituições com poder de polícia e na adaptação dos indicadores de governança descritos por Kaufmann et al. (2009), Fonseca e Bursztyn (2009), Cruz e Marques (2014) e Rodrigues (2014). Por fim, a sadia qualidade de vida é interpretada a partir dos preceitos elencados no artigo 6o da CF/1988, os quais são complementares a conceitos pacificados na literatura sobre qualidade de vida (HERCULANO, 1994; FELECE e PERRY, 1995; DIENER e SUH, 1997).

O artigo traz pelo menos três contribuições: i) adota uma abordagem diferenciada da análise da qualidade de vida em comunidades rurais, a partir de indicadores voltados para a mensuração da "sadia" qualidade de vida, termo empregado na Constituição Federal brasileira de 1988 ao se referir ao papel do poder público e da coletividade na defesa do meio ambiente, ii) chama atenção para a importância de um sinergismo entre os conceitos de capital social, empoderamento e governança ambiental, aqui colocados e, geralmente, estudados de forma isolada nas análises empíricas realizadas nas áreas rurais e iii) mostra que a análise teórica dos conceitos trabalhados pode não traduzir as relações conceituais quando estas são testadas empiricamente nas comunidades rurais.

O artigo está estruturado em cinco seções, incluindo a introdução. Na segunda seção são discutidas as inter-relações entre os conceitos trabalhados. Em seguida, os procedimentos metodológicos adotados. Na quarta seção são apresentados os resultados obtidos a partir de pesquisa de campo junto às comunidades rurais visitadas. Por fim, a quinta seção traz as considerações finais do estudo.

\section{As inter-relações entre capital social, empoderamento e governança ambiental, na sadia qualidade de vida}

Nos últimos anos tem se intensificado o debate a respeito dos conceitos de capital social, empoderamento e governança ambiental. Contudo, não se observa a preocupação com a integração desses conceitos como fator de promoção de condição de desenvolvimento e qualidade de vida. De fato, colocando o conceito de qualidade de vida na perspectiva de direito social fundamental, tal qual como foi inserido na CF 1988, agora com a denominação "sadia qualidade de vida", nota-se que o debate ainda está em fase embrionária.

Segundo Baquero (2007), o capital social e o empoderamento são conceitos multidimensionais, que encontram nos campos do desenvolvimento sustentável, 
714 - Confluência do Capital Social, Empoderamento e Governança Ambiental na Sadia Qualidade de Vida em Comunidades Rurais no Ceará

da gestão dos recursos naturais e da governança ambiental um fértil campo de aplicação e atuação com vistas a prover a qualidade de vida com equilíbrio ecológico. Nesse cenário, percebe-se que "a expressão governance visa aprofundar o conhecimento das condições que garantem um Estado eficiente, deslocando o foco estritamente econômico da ação estatal para uma dimensão mais ampla e abrangível das condições sociais e políticas da gestão pública" (DINIZ, 1995, p. 400). Isso se dá em função de que qualquer programa de governo tem que estar balizado no exercício do poder dever compartilhado.

Nessa perspectiva, Mertens et al. (2011) lembram que as redes sociais e o capital social podem favorecer o fortalecimento de processos de governança, no sentido de apontar mecanismos de políticas públicas locais que tornem possível o uso sustentável dos recursos naturais. Os autores Pretty e Ward (2001) e Diettz et al. (2003) corroboram com essa ideia ao afirmar que o capital social dos atores pode favorecer os processos de governança ambiental, pois promove relações de confiança e reciprocidade na troca de informação e recursos, criação de normas, diminuição dos custos de fiscalização e construção de uma visão de futuro compartilhada. Bodin e Crona (2009) apontam para o potencial que as redes sociais detêm para capitalizar atores em diversas categorias e níveis para elaborar, executar e monitorar estruturas adaptáveis de governança ambiental.

Fonseca; Bursztyn (2009) relatam que o investimento na governança implica no fortalecimento de um processo político mais abrangente, eficiente e justo. "A ideia de governança promove o pluralismo político, a eficiência e a transparência nas escolhas e decisões públicas, procurando alcançar um grande número de atores e processos" (p. 20). E que, apoiado nos conceitos de capital social, que se referem aos aspectos da organização social, tais como redes de comunicações, regras de confiança, que facilitam a coordenação e cooperação para obtenção de benefícios mútuos:

fortes tradições de engajamento cívico - presença do eleitor nas urnas, público leitor de jornais, participação em corais e círculos literários, Lions Club e clubes de futebol - são as marcas de uma região próspera. [...] Tais comunidades cívicas valorizam a solidariedade, a participação cívica e a integridade [...] a democracia funciona (PUTNAM, 2001, p. 54-55).

Para Baquero (2007), o capital social pode ser usado em confluência com o empoderamento como processo e resultado, pode ser concebido como emergindo de um processo de ação social, no qual os indivíduos tomam posse de suas próprias vidas pela interação com outros indivíduos, gerando pensamento crítico em relação à realidade, favorecendo a construção das capacidades pessoal e social e possibilitando a transformação de relações sociais e poder. No texto, As múltiplas faces da desigualdade: capital social e empoderamento na América Latina, publicado em 2007, ele elege duas fontes vitais para aferir empoderamento as pessoas.

Em primeiro lugar, identificam-se as fontes institucionais-formais (partidos, congresso, judiciário) como elemento de empoderamento institucional, ou seja, a disponibilidade legal e formal de organizações que as pessoas têm para encaminhar suas reivindicações. A democracia representativa por meio de seus procedimentos e regras formais de proteção dos direitos políticos, sociais e civis é considerado o eixo catalisador que dá voz e poder a polis. Num outro grupo se identificam os fatores não institucionais de empoderamento. [...] as organizações e atores sociais que contribuem para dar protagonismo aos cidadãos, a margem das instituições convencionais de medição política (partidos políticos), com estratégias de empoderamento informal (BAQUERO, 2007, p. 307).

Para Nazzari (2003), assim como no empoderamento, o capital social pode ser agrupado em três níveis: no nível individual, com atuação no mercado e nas instituições sociais (horizontal e vertical); no nível de pertencimento e identificação dos indivíduos nas redes sociais, facilitando bens e recursos; e no nível comunitário coletivo, regulando a vida social. "Em algumas fontes de capital social é possível identificar as atividades voluntárias e a confiança interpessoal e institucional" (p. 165). Todavia, nos parece viável a extrapolação desse conteúdo, alcançando, nesses níveis, a governança ambiental, nas normas que regulam o mercado e a vida social, como também os indicadores sociais, no nível de pertencimento e acesso a bens e recursos. 


\section{Procedimentos metodológicos}

\section{1. Área de estudo e fonte dos dados}

No Ceará, o Plano de Desenvolvimento Regional (PDR, 2000) assinala que a microrregião do Baixo Jaguaribe foi beneficiada pela interiorização do desenvolvimento e a descentralização das atividades governamentais iniciadas em 2000 e continuadas na gestão 2003-2006, culminando na implementação de um planejamento regional que buscou diminuir os desequilíbrios demográficos e econômicos observados entre a região metropolitana de Fortaleza (RMF) e as demais regiões do estado. Com isso, tratou de elencar um conjunto de iniciativas voltadas à construção do desenvolvimento, pautado nas atividades geradoras de emprego e renda, no incentivo da produção agrícola e o fortalecimento da rede urbana polarizada pelas cidades principais: Limoeiro do Norte, Morada Nova e Russas.

Nesse contexto, evidencia-se a importância de um ambiente onde interajam capital social, empoderamento e governança ambiental a fim de potencializar quaisquer medidas de desenvolvimento. Essa premissa motivou a escolha da microrregião para o estudo. Assim, foram selecionadas 31 comunidades rurais que, juntas, estão se beneficiando direta ou indiretamente dos bens e serviços gerados a partir da implementação do projeto perímetro irrigado no Polo de Desenvolvimento Integrado Tabuleiro de Russas.

A semelhança entre as comunidades favoreceu a adoção da técnica de amostragem por saturação, que considera que a coleta de dados pode ser interrompida quando se percebe que novos elementos úteis para subsidiar a pesquisa em questão não são mais obtidos a cada observação coletada (FONTANELLA et al., 2011; GOBO, 2007). Foram utilizados dados obtidos por meio de coleta direta, a partir de formulários aplicados junto às pessoas que exercem ou exerceram atividades de representação ou liderança nessas comunidades, o que a priori lhes conferem autoridade e conhecimento para fornecer as informações solicitadas.

\subsection{Métodos de análise dos dados}

\subsubsection{A operacionalização dos conceitos}

Os conceitos de capital social, empoderamento, governança ambiental e sadia qualidade de vida foram operacionalizados por meio da construção de quatro índices agregados compostos. Por tratar-se de conceitos multidimensionais, optou-se por representar cada um deles por meio de um sistema de indicadores compostos por diferentes variáveis. $\mathrm{O}$ uso de indicadores para a mensuração de conceitos é uma ferramenta bastante utilizada em estudos empíricos. Para Bellen (2004), a palavra indicador deriva do latim, e significa destacar, descobrir, estimar, apontar, anunciar ou revelar alguma coisa. Um bom indicador deverá apresentar algumas propriedades, tidas como desejáveis: relevância, validade, confiabilidade, cobertura, sensibilidade, especificidade, facilidade para obtenção, comunicabilidade (NARDO et al., 2005).

No Quadro 1, a seguir, o indicador grupos e redes sociais é fundamentado no fato de que o capital social é constituído pelo conjunto de recursos atuais ou potenciais que estão ligados à posse de uma rede durável de relações mais ou menos institucionalizadas de conhecimento e reconhecimento. O capital social é consequência natural de indivíduos que se relacionam a partir de atividade que requer sociabilidade, o que chama a atenção para os laços sociais e para a cultura, por deter informações e conhecimento da realidade social.

Comunidade Cívica, Normas e Sistemas de Participação compreendem características da organização social que contribuem para aumentar a eficiência da sociedade, facilitando as ações coordenadas. Enquanto Ação Coletiva, Reciprocidade e Solidariedade referem-se à associação, isto é, o capital pertence a uma coletividade ou a uma comunidade; ele é compartilhado e não pertence a um indivíduo. Não se gasta com o tempo, ao contrário, sua utilização o faz crescer. Por fim, o indicador Compromisso, Confiança e Confiabilidade trata de algo que pode mudar países em suas áreas econômica, ambiental, social, política e cultural. O capital social diz respeito ao eu com o outro. Expressa a minha atitude com o outro.

Para efeito do conceito de empoderamento (empowerment) nas comunidades estudadas, Friedman (1992) e Freire $(1986,1988)$ foram referenciados, dada a forma como esses dois autores abordam o termo. Em Friedman, empowerment se constitui em mecanismo de equilíbrio de força que reveste o agente de poder para participar e acompanhar as ações e decisões na sociedade civil. Para Freire, o termo empoderamento foi introduzido como estratégia de transformação social, 
716 - Confluência do Capital Social, Empoderamento e Governança Ambiental na Sadia Qualidade de Vida em Comunidades Rurais no Ceará

Quadro 1. Indicadores de capital social e fundamentação teórica

\begin{tabular}{|c|c|c|}
\hline Indicador & Variáveis & $\begin{array}{c}\text { Fundamentação } \\
\text { teórica }\end{array}$ \\
\hline \multirow{14}{*}{$\begin{array}{l}\text { Grupos e redes } \\
\text { sociais }\end{array}$} & 1. Existe na comunidade grupo de apoio (a vulneráveis). & \multirow{14}{*}{$\begin{array}{l}\text { Bourdieu (1980) } \\
\text { Colleman }(1990) \\
\text { Putnam }(1997)\end{array}$} \\
\hline & 2. Grupo de jovens. & \\
\hline & 3. Grupo religioso, evangélico, espiritual. & \\
\hline & 4. Grupo ou associação de moradores. & \\
\hline & 5. Grupos de amigos ligados por uma causa qualquer. & \\
\hline & 6. Conselho comunitário. & \\
\hline & 7. Conselho de pais. & \\
\hline & 8. Secretaria (educação, saúde, meio ambiente, outras). & \\
\hline & 9. Associação de produtores/Colônia de pescadores. & \\
\hline & 10. Sindicato de trabalhadores da área rural & \\
\hline & 11. Existe ONGs. & \\
\hline & 12. Cooperativa de serviço, produção, comercialização, créditos outros. & \\
\hline & $\begin{array}{l}\text { 13. Existem empresas (particular, pública ou mista, destinada a produção e/ou venda } \\
\text { de produtos ou serviços). }\end{array}$ & \\
\hline & 14. Existem corporações (produções sob a fiscalização do Estado). & \\
\hline \multirow{7}{*}{$\begin{array}{l}\text { Comunidade } \\
\text { Cívica, Normas e } \\
\text { Sistemas de Partici- } \\
\text { pação }\end{array}$} & 15. Existe participação da comunidade nas ações de interesses coletivos. & \multirow{7}{*}{$\begin{array}{l}\text { Colleman }(1990) \\
\text { Evans (1996) } \\
\text { Putnam (1997) } \\
\text { Milani (2003) }\end{array}$} \\
\hline & $\begin{array}{l}\text { 16. Existe engajamento na operacionalização de atividades coletivas (preparação, } \\
\text { execução e arrumação) em eventos diversos (festas, cultos, eleição etc.). }\end{array}$ & \\
\hline & $\begin{array}{l}\text { 17. As normas e sistemas de participação instituídas na comunidade gozam de lega- } \\
\text { lidade e legitimidade. }\end{array}$ & \\
\hline & $\begin{array}{l}\text { 18. Presença do eleitor nas urnas, público leitor de jornais ou outro meio de comuni- } \\
\text { cação. }\end{array}$ & \\
\hline & $\begin{array}{l}\text { 19. Participação em corais, círculos literários e eventos culturais, Lions Clube, clube } \\
\text { de futebol. }\end{array}$ & \\
\hline & $\begin{array}{l}\text { 20. A comunidade preza e reverencia democraticamente as normas e os sistemas de } \\
\text { participação de todos com seus direitos assegurados (voz e voto). }\end{array}$ & \\
\hline & $\begin{array}{l}\text { 21. A comunidade participa da composição de sua representação ou liderança por } \\
\text { meio de eleição. }\end{array}$ & \\
\hline \multirow{6}{*}{$\begin{array}{l}\text { Ação Coletiva, } \\
\text { Reciprocidade e } \\
\text { Solidariedade }\end{array}$} & 22. A comunidade preza a ação coletiva em detrimento da individual. & \multirow{6}{*}{$\begin{array}{l}\text { Putnam (1997) } \\
\text { Ostrom (1997) }\end{array}$} \\
\hline & 23. A comunidade se dispõe quando necessário a regime de mutirão. & \\
\hline & 24. É comum exploração coletiva em cada etapa da produção. & \\
\hline & $\begin{array}{l}\text { 25. Existe na comunidade algum sistema que facilite acesso e inclusão dos morado- } \\
\text { res a políticas de crédito e direitos básicos. }\end{array}$ & \\
\hline & 26. A coletividade pratica ações solidárias no dia a dia. & \\
\hline & $\begin{array}{l}\text { 27. Existe reciprocidade e solidariedade por parte do prestador de serviço e do be- } \\
\text { neficiário. }\end{array}$ & \\
\hline \multirow{5}{*}{$\begin{array}{l}\text { Compromisso, } \\
\text { Confiança e } \\
\text { Confiabilidade }\end{array}$} & $\begin{array}{l}\text { 28. Os membros confiam uns nos outros e, em consequência, respaldam essa con- } \\
\text { fiança em ganhos para a comunidade. }\end{array}$ & \multirow[t]{5}{*}{$\begin{array}{l}\text { Johannpeter (2012) } \\
\text { Putnam (2002) }\end{array}$} \\
\hline & $\begin{array}{l}\text { 29. A comunidade costuma respeitar compromissos e agendamentos interno e ex- } \\
\text { terno. }\end{array}$ & \\
\hline & 30. A comunidade confia seus encaminhamentos às suas lideranças locais. & \\
\hline & 31. Existe reciprocidade entre os representantes e representados. & \\
\hline & $\begin{array}{l}\text { 32. A comunidade se faz confiável na capacidade de desempenhar sistematicamente } \\
\text { suas funções de acordo com o que é deliberado democraticamente pelos mora- } \\
\text { dores. }\end{array}$ & \\
\hline
\end{tabular}

Fonte: Elaboração própria. 
buscando habilitar grupos sociais excluídos para definir e reivindicar coletivamente seus direitos na sociedade civil (ZANK et al., 2012). Wallerstein e Bernstein (1994) reconheceram a ocorrência do empoderamento nos níveis individual, organizacional e comunitário.

O empoderamento comunitário tem como característica fomentar o estado de espírito para a participação e assunção de papéis que facilitam o engajamento cívico na condução dos problemas macrossociais, resultados de lutas e conquistas que melhoram as condições de vida para a comunidade. Assim, como expressa o Quadro 2, foram selecionados três indicadores para compor o empoderamento: i) empoderamento político (possui como principal característica fortalecer a autoestima e promover a autoconfiança dos indivíduos buscando melhorar a participação político-organizacional e contribuir para melhorar a realidade local com vistas à promoção da qualidade de vida, ii) empoderamento social (marcado pela disposição de participar e assumir papéis que permitam o engajamento político na condução dos problemas macrossociais que resultem de lutas e conquistas para transformar a realidade em favor de melhores condições de vida para todos e iii) empoderamento psicológico (expressa a ideia de força interior, autocontrole e sentimento de felicidade no engajamento coletivo que influencia a realidade contextual).

Quadro 2. Indicadores de empoderamento e fundamentação teórica

\begin{tabular}{|c|c|c|}
\hline Indicador & Variáveis & $\begin{array}{c}\text { Fundamentação } \\
\text { teórica }\end{array}$ \\
\hline \multirow{7}{*}{$\begin{array}{l}\text { Empoderamento } \\
\text { político }\end{array}$} & 1. A comunidade acredita ser vetor de mudanças pela participação direta nas assembleias. & \multirow{7}{*}{\begin{tabular}{|l} 
Narayan (2002) \\
Perrez (2004) \\
Rich et al. (1995) \\
Baquero e Baquero \\
(2007) \\
\\
\end{tabular}} \\
\hline & $\begin{array}{l}\text { 2. A comunidade acredita que a representação das lideranças é a melhor forma de par- } \\
\text { ticipaça popular. }\end{array}$ & \\
\hline & $\begin{array}{l}\text { 3. A comunidade acredita ser possível a sadia qualidade de vida entre capitalismo e } \\
\text { democracia. }\end{array}$ & \\
\hline & $\begin{array}{l}\text { 4. A comunidade busca o acesso a bens materiais ou imateriais a partir da percepção dos } \\
\text { moradores como garantidores de qualidade de vida. (Proativo) } \\
\end{array}$ & \\
\hline & $\begin{array}{l}\text { 5. A comunidade só luta quando se sente ameaçada ou negada nos seus direitos funda- } \\
\text { mentais. (Reativo) }\end{array}$ & \\
\hline & $\begin{array}{l}\text { 6. A comunidade acredita ser o voto secreto a mais democrática das formas de repre- } \\
\text { sentação popular. }\end{array}$ & \\
\hline & $\begin{array}{l}\text { 7. A comunidade tem consciência dos direitos e deveres que a ela foi imputado com a Cons- } \\
\text { tituição Federal de } 1988 \text { especialmente no que prescrevem os artigos } 225,5^{\circ}, 1^{\circ} \text { III e } 6^{\circ} \text {. }\end{array}$ & \\
\hline \multirow{6}{*}{$\begin{array}{l}\text { Empoderamento } \\
\text { Social }\end{array}$} & 8. A comunidade se sente responsável pela condição atual de acesso aos direitos sociais. & \multirow{6}{*}{\begin{tabular}{|l} 
Carvalho (2004) \\
Baquero (2005) \\
Hermany e Costa \\
$(2009)$ \\
\end{tabular}} \\
\hline & $\begin{array}{l}\text { 9. A disposição de participar e assumir papéis de controle e liderança melhora a condu- } \\
\text { ção do processo coletivo. }\end{array}$ & \\
\hline & $\begin{array}{l}\text { 10. Acredita que o coletivo garante maior eficácia política, justiça social, equilíbrio am- } \\
\text { biental e melhoria da qualidade de vida. }\end{array}$ & \\
\hline & $\begin{array}{l}\text { 11. Existem o uso e a apropriação de espaços públicos de convivência e sociabilidade, que } \\
\text { integram os indivíduos a comunidade. }\end{array}$ & \\
\hline & 12. A comunidade promove ações de inclusão e fortalecimento para os seus moradores. & \\
\hline & $\begin{array}{l}\text { 13. A comunidade consegue conciliar conquistas sociais, preservação ambiental, políticas } \\
\text { de inclusão e sadia qualidade de vida sem perder a vivência do local? (Costumes e } \\
\text { tradições) }\end{array}$ & \\
\hline \multirow[t]{6}{*}{$\begin{array}{l}\text { Empoderamento } \\
\text { Psicológico }\end{array}$} & $\begin{array}{l}\text { 14. A comunidade acredita que é capaz de mudar suas crenças em relação à submissão e } \\
\text { despertar para lutar por direitos. }\end{array}$ & \multirow{6}{*}{$\begin{array}{l}\text { Friedman (1992) } \\
\text { Wallerstein e } \\
\text { Bernstein (1994) } \\
\text { Romano e Antunes } \\
\text { (2002) } \\
\text { Schiavo e Moreira } \\
\text { (2005) } \\
\text { Rich et al. (1995) }\end{array}$} \\
\hline & $\begin{array}{l}\text { 15. Os membros da comunidade adotam um posicionamento crítico em face dos aconte- } \\
\text { cimentos que dizem respeito à promoção da sadia qualidade de vida. }\end{array}$ & \\
\hline & $\begin{array}{l}\text { 16. A comunidade acredita que o acesso a direitos sociais fortalece a relação de poder } \\
\text { para a cidadania. }\end{array}$ & \\
\hline & $\begin{array}{l}\text { 17. Na comunidade percebe-se um comportamento de autoestima se refletindo em auto- } \\
\text { nomia expressa no direito de ir e vir, bem como evitando o abuso físico e as violações } \\
\text { ao seu direito a ter, ser e amar. }\end{array}$ & \\
\hline & 18. Acredita que o autocontrole e o sentimento de felicidade ajuda no engajamento coletivo. & \\
\hline & $\begin{array}{l}\text { 19. Na comunidade, a autoconfiança é um elemento de conquistas (mudanças em relação } \\
\text { à consciência, aos seus direitos e capacidade de ação e reação na construção de políti- } \\
\text { cas públicas mais eficazes). }\end{array}$ & \\
\hline
\end{tabular}

Fonte: Elaboração própria. 
718 - Confluência do Capital Social, Empoderamento e Governança Ambiental na Sadia Qualidade de Vida em Comunidades Rurais no Ceará

Para verificar a governança ambiental foram utilizados os indicadores elencados no Quadro 3. Iniciando com o indicador Participação e Responsabilidade, que representa a distribuição de poder entre instituições de governo; a legitimidade e a autoridade dessas instituições; as regras e normas que determinam quem detém o poder e como são tomadas as decisões sobre o exercício da autoridade; relações de responsabilização entre repre- sentantes, cidadãos e agências do Estado, habilidade do governo em fazer políticas, gerir assuntos administrativos e fiscais do Estado e prover bens e serviços; e impacto das instituições sobre o bem-estar público. Estabilidade Política e Legitimidade usa a ideia de que a Governança promove o pluralismo político, a eficiência e a transparência nas escolhas e decisões públicas, visando incluir uma ampla gama de atores sociais e processos.

Quadro 3. Indicadores de governança ambiental e fundamentação teórica

\begin{tabular}{|c|c|c|}
\hline Indicador & Variável & $\begin{array}{c}\text { Fundamentação } \\
\text { teórica }\end{array}$ \\
\hline \multirow{10}{*}{$\begin{array}{l}\text { Participação e } \\
\text { responsabilidade }\end{array}$} & 1. Participação dos eleitores nas últimas eleições para prefeito, governador e presidente & \multirow{10}{*}{$\begin{array}{l}\text { Grindle (2004) } \\
\text { Fonseca e } \\
\text { Bursztyn (2009) } \\
\text { Dallabrida (2015) }\end{array}$} \\
\hline & 2. Acompanhamento da comunidade em relação ao candidato eleito durante o seu mandato & \\
\hline & $\begin{array}{l}\text { 3. Frequência de debates, reuniões para discussão e conscientização quanto à definição de um perfil de } \\
\text { candidato que atenda os interesses coletivos }\end{array}$ & \\
\hline & 4. Consciência dos membros da comunidade quanto à força do seu voto para os interesses coletivos & \\
\hline & 5. Participação da comunidade na representação política local (Prefeitura, câmara etc.) & \\
\hline & $\begin{array}{l}\text { 6. Transparência por parte da condução dos trabalhos e prestação de contas pelo prefeito e secretariado, } \\
\text { câmara e demais lideranças }\end{array}$ & \\
\hline & 7. Transparência por parte da condução dos trabalhos e prestação de contas na Câmara Municipal & \\
\hline & $\begin{array}{l}\text { 8. Transparência da parte dos representantes e lideranças na disponibilização de informação relevantes } \\
\text { para a comunidade }\end{array}$ & \\
\hline & $\begin{array}{l}\text { 9. Participação da comunidade nos processos de elaboração e planejamento das políticas (públicas e se- } \\
\text { toriais) para a promoçãa da sadia qualidade de vidas (Direitos sociais- art. } 6^{\circ} \mathrm{CF} \text {, Iluminação pública, } \\
\text { estradas, indústrias etc.). }\end{array}$ & \\
\hline & 10. Participação da comunidade nos ganhos para a sadia qualidade de vida local & \\
\hline \multirow{5}{*}{$\begin{array}{l}\text { Estabilidade } \\
\text { Política e } \\
\text { Legitimidade }\end{array}$} & $\begin{array}{l}\text { 11. Compromisso dos candidatos eleitos quanto aos interesses da comunidade no que diz respeito a promo- } \\
\text { ção da sadia qualidade de vida. }\end{array}$ & \multirow{5}{*}{$\begin{array}{l}\text { Mcfarland (2007) } \\
\text { Kim et al. (2005) } \\
\text { Dallabrida (2015) }\end{array}$} \\
\hline & 12. Continuidade política de vereadores eleitos por seguidos pleitos na câmara e apoiado pela comunidade & \\
\hline & $\begin{array}{l}\text { 13. Legitimidade dos representantes e líderes da comunidade perante os moradores e instituições por estes } \\
\text { representados (empatia junto à comunidade) }\end{array}$ & \\
\hline & $\begin{array}{l}\text { 14. Existência de permissão para que representantes e/ou lideres permaneçam por tempo indeterminado } \\
\text { em cargo público }\end{array}$ & \\
\hline & $\begin{array}{l}\text { 15. A comunidade considera que a quantidade de tempo de um vereador ou líder no exercício da função } \\
\text { lhe garante legitimidade }\end{array}$ & \\
\hline \multirow{6}{*}{$\begin{array}{l}\text { Eficácias da } \\
\text { Governança }\end{array}$} & 16. As lideranças têm correspondido aos anseios da comunidade no que diz respeito a bens e direitos & \multirow{6}{*}{\begin{tabular}{|l} 
Fonseca e \\
Bursztyn (2009) \\
Harris (2001) \\
Colleman (1986)
\end{tabular}} \\
\hline & $\begin{array}{l}\text { 17. A comunidade discute e participa da elaboração e execução do planejamento estratégico da cidade junto } \\
\text { a prefeitura e demais entidades }\end{array}$ & \\
\hline & 18. As políticas públicas têm conseguido chegar efetivamente à comunidade de forma satisfatória & \\
\hline & $\begin{array}{l}\text { 19. A comunidade é beneficiada por melhorias obtidas através de políticas setoriais (estradas, iluminação } \\
\text { pública etc.) }\end{array}$ & \\
\hline & $\begin{array}{l}\text { 20. A comunidade percebe melhoria na qualidade dos serviços municipais quando ela é chamada a partici- } \\
\text { par com demandas específicas }\end{array}$ & \\
\hline & $\begin{array}{l}\text { 21. A comunidade consegue perceber e compatibilizar política de investimentos com necessidades aliadas a } \\
\text { tarifas e taxas cobradas por serviços prestados pelo município de forma justa e adequada }\end{array}$ & \\
\hline \multirow{5}{*}{$\begin{array}{l}\text { Estado de } \\
\text { Direito }\end{array}$} & 22. Confiança da comunidade em suas instituições públicas & \multirow{5}{*}{$\begin{array}{l}\text { Kaufmann et al. } \\
\text { (2009) } \\
\text { Koppenjan et al. } \\
(2010)\end{array}$} \\
\hline & 23. Eficiência na prestação de serviços básicos por parte do Poder público & \\
\hline & $\begin{array}{l}\text { 24. Nível de conhecimento da comunidade em relação aos "remédios constitucionais" garantidores do livre } \\
\text { exercício de cidadania (habeas corpus, habeas datas, referendum, plebiscito, mandado de segurança e } \\
\text { mandado de injunção) em caso de ameaça ou lesão a direito fundamental }\end{array}$ & \\
\hline & $\begin{array}{l}\text { 25. Nível de conhecimento da comunidade em relação ao seu direito de peticionar em caso de negação de } \\
\text { um dos direitos elencados nos artigos } 225,5^{\circ}, 1^{\circ} \mathrm{III} \text { e } 6^{\circ} \text {, enquanto direitos fundamentais e por isso auto- } \\
\text { aplicáveis. (Ação civil pública ou Ação Popular) }\end{array}$ & \\
\hline & $\begin{array}{l}\text { 26. Sentimento da comunidade quanto a ser representada e respeitada na sua dignidade de pessoa humana } \\
\text { pelas instituições de direito }\end{array}$ & \\
\hline
\end{tabular}




\begin{tabular}{|c|c|c|}
\hline Indicador & Variável & $\begin{array}{l}\text { Fundamentação } \\
\text { teórica }\end{array}$ \\
\hline \multirow[t]{8}{*}{$\begin{array}{l}\text { Qualidade } \\
\text { Regulatória }\end{array}$} & $\begin{array}{l}\text { 27. Existência de necessidade de estatuto, normatização ou regulamentando disciplinando o sistema de par- } \\
\text { ticipação da comunidade e seus representantes }\end{array}$ & \multirow{8}{*}{\begin{tabular}{|l} 
Fonseca e \\
Bursztyn (2009) \\
Dallabrida (2015)
\end{tabular}} \\
\hline & $\begin{array}{l}\text { 28. Existência de reverência às instituições e pessoas nos campos moral, ético, religiosa, jurídico, cultural e } \\
\text { natural }\end{array}$ & \\
\hline & $\begin{array}{l}\text { 29. Percepção da comunidade quanto ao fato de a existência de normas constitucionais e infraconstitucio- } \\
\text { nais, como também os decretos, as portarias, notas técnicas, receituários etc. ter conseguido efetivar os } \\
\text { direitos sociais, garantidores de piso vital mínimo da dignidade da pessoa humana }\end{array}$ & \\
\hline & $\begin{array}{l}\text { 30. Percepção da comunidade quanto ao fato de a autonomia dos três poderes (Legislativo, Judiciário e } \\
\text { Executivo), independentes e harmônicos entre si, constituírem uma forma negativa na acessibilidade } \\
\text { dos direitos sociais ou fundamentais }\end{array}$ & \\
\hline & $\begin{array}{l}\text { 31. Acompanhamento, por parte da comunidade, dos Entes (União, Estado e Município) no que se refere } \\
\text { ao cumprimento de práticas e ações regulatórias à eficácia de uma sadia qualidade de vida em um meio } \\
\text { ambiente ecologicamente equilibrado }\end{array}$ & \\
\hline & $\begin{array}{l}\text { 32. Planejamento e execução do licenciamento e fiscalização de competência em seus empreendimentos } \\
\text { locais (públicos e privados), por parte do poder municipal }\end{array}$ & \\
\hline & $\begin{array}{l}\text { 33. Acompanhamento da criação e manutenção de órgãos competentes para licenciar e fiscalizar esses } \\
\text { empreendimentos. (Tais como: Secretarias ou Conselhos de Meio Ambiente, discussão de projetos de } \\
\text { prevenção ou preservação ambiental, Estudo de impacto Ambiental ou Relatório de impacto ambiental } \\
\text { EIA-RIMA, Disciplina de Educação ambiental nas escolas, Comitês de Bacia Hidrográficas, entre outros). }\end{array}$ & \\
\hline & $\begin{array}{l}\text { 34. Existência de monitoramento e, quando necessário mediante percepção ou cobrança da comunidade, } \\
\text { investimento na adoção de medidas mitigadoras visando cessar ou evitar lesão ou ameaça a lesão do } \\
\text { direito ao meio ambiente e a sadia qualidade de vida. }\end{array}$ & \\
\hline
\end{tabular}

Fonte: Elaboração própria.

Eficácias da Governança capta conceitos e critérios como empowerment (empoderamento), participação, capital social, accountability (responsabilização), descentralização, educação de qualidade, combate à corrupção, eficácia dos mercados, mão de obra qualificada, igualdade de gênero, respeito à propriedade e à livre iniciativa, distribuição equitativa de renda, entre outros, que fazem parte de uma agenda cada vez mais ampla e repleta de boas intenções. O Estado de Direito se refere à percepção sobre o grau de confiança e de cumprimento das regras da sociedade por parte dos agentes, em particular, a qualidade da execução de contratos de propriedade, a polícia, os tribunais, assim como a probabilidade de crime e violência. Por fim, a Qualidade Regulatória envolve atributos como participação, descentralização, responsabilização e equidade entre os atores que dão à noção de governança um conteúdo de legitimidade e pragmatismo, abrindo espaço para uma regulação que leve em conta fatores extra econômicos.

Os indicadores de sadia qualidade de vida foram selecionados com base em fundamentação teórica e no artigo 6º , da CF/1988, por conta da dinâmica de acessi- bilidade prestacional do Estado para compor o piso vital mínimo, ou seja, sua sobrevivência material, enquanto direito fundamental da pessoa humana. Sem esta contextualização epistemológica se perde a hermenêutica do conteúdo do que seja a sadia qualidade de vida, na perspectiva dos direitos fundamentais sociais. No que, para se ter assegurado o piso vital mínimo, há que se contar com um somatório de elementos materiais e imateriais que compõem a vida orgânica e inorgânica de qualquer manifestação natural, humana ou artificial que ocupa interespaço, podendo ser ou vir a ser encontrado ou percebido em qualquer uma de suas manifestações.

Assim, entende-se que os indicadores de sadia qualidade de vida devem refletir as condições do cidadão para satisfazer necessidades básicas, evidenciadas no princípio da igualdade para todos. $\mathrm{O}$ acesso a bens e direitos como piso vital mínimo para a dignidade da pessoa humana, conforme estabelecido no artigo $6^{\circ}$, da CF/1988 se fundamenta nos direitos sociais ou fundamentais. Assim, foram selecionados os 10 indicadores elencados no artigo constitucional para compor a sadia qualidade de vida (Quadro 4). 


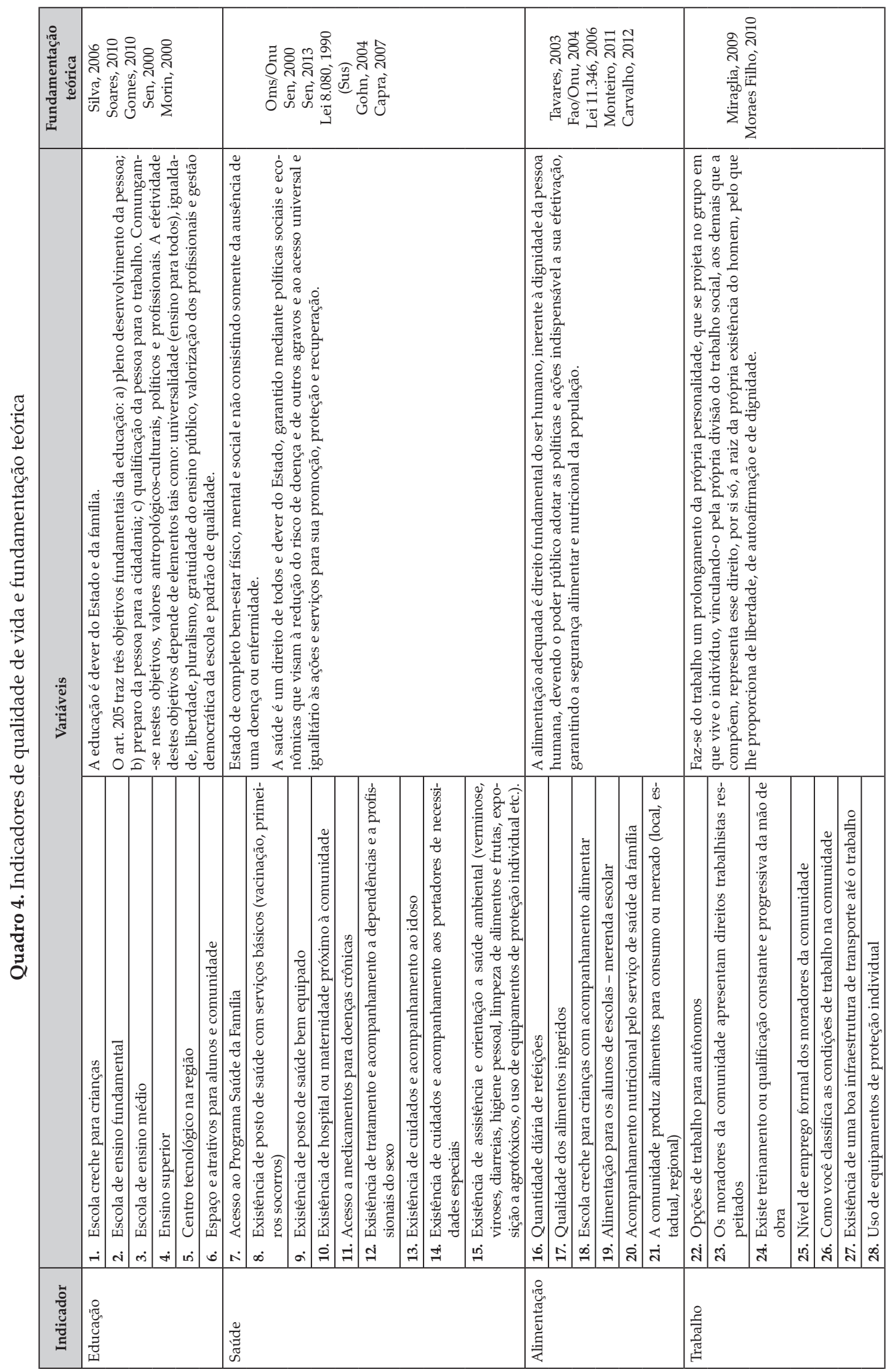




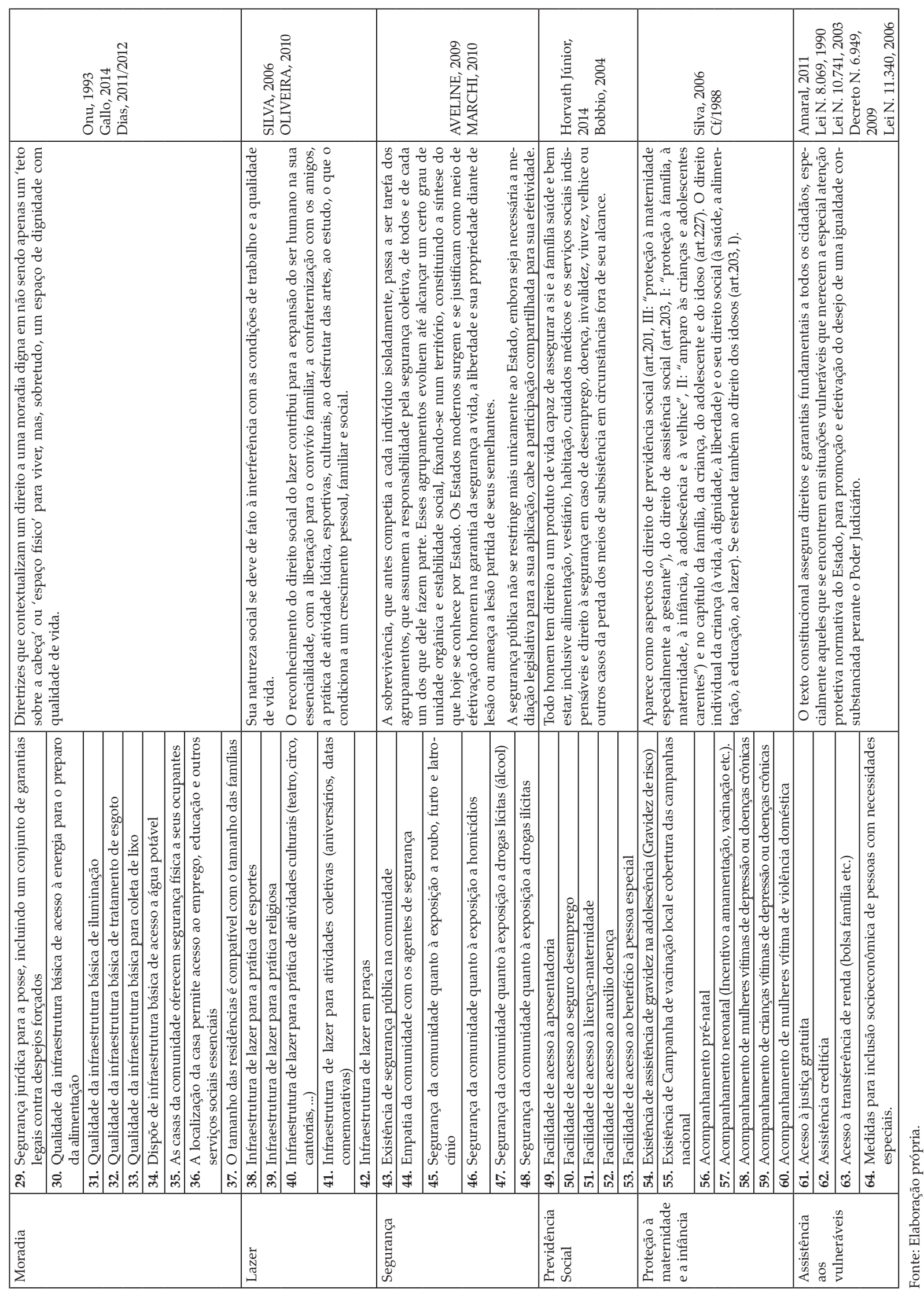


As variáveis apresentadas nos quadros supracitados foram avaliadas considerando um conjunto de escores organizados em ordem crescente, partindo-se da situação em que a variável é pior avaliada até a situação em que atinge sua melhor avaliação, segundo a opinião dos representantes das comunidades visitadas. Os escores variaram de 0 a 5 , conforme a escala: Ausente na comunidade $=0$; Muito ruim $=1$; Ruim $=2$; Regular $=3$; Bom $=4$ e Muito bom $=5$. Assim cada indicador recebeu um valor, calculado segundo Sousa et al (2005):

$$
\text { Indicador } r_{i j}=\frac{1}{n} \sum_{j=1}^{n}\left[\frac{1}{m} \sum_{p=1}^{m} \frac{E_{p i j}}{E \max _{p i}}\right]
$$

Sendo:

Indicador $_{i j}=$ valor do $i$-ésimo indicador componente do conceito, correspondente à j-ésima comunidade;

$E_{p i j}=$ Escore atribuído à $p$-ésima variável do i-ésimo indicador, correspondente à j-ésima comunidade;

Emax $_{p i}=$ Escore máximo da $p$-ésima variável do i-ésimo indicador;

$i=1, \ldots, w$ (indicador correspondente ao conceito) $(w=10$ para ISQV - Índice de Sadia Qualidade de Vida, $w=4$ para ICS - Índice de Capital Social, $w=3$ para IE - Índice de Empoderamento e $w=5$ para IGA - Índice de Governança Ambiental);

$p=1, \ldots, m$ (variáveis componentes do i-ésimo indicador);

$j=1, \ldots, n$ (comunidades visitadas $=31$ ).

Após a agregação das variáveis foi realizada uma nova agregação, agora dos indicadores, para a obtenção dos índices agregados. Para tanto, foi adotada a equação:

$$
\text { Indice Agregado }=\frac{1}{w} \sum_{i=1}^{w} \text { Indicador }_{i}
$$

Foram calculados quatro índices agregados: ISQV (Índice de Sadia Qualidade de Vida), ICS (Índice de Capital Social), IE (Índice de Empoderamento) ou IGA (Índice de Governança Ambiental).

Os valores dos indicadores e índices podem variar de 0 (zero) a 1 (um), sendo adotado a seguinte parametrização: Muito Ruim: $0 \leq$ valor obtido $\leq 0,2$; Ruim: $0,2<$ valor obtido $\leq 0,4$; Regular: $0,4<$ valorobtido $\leq 0,6$; Bom: $0,6<$ valor obtido $\leq 0,8$ e Muito Bom: $0,8<$ valor obtido $\leq 1,0$.

\subsubsection{A análise da confluência}

O termo confluência, com base nos estudos de Carmo (2008), se refere à importância das ligações e das redes sociais como elementos centrais na produção de interesses e articulações de objetivos comuns. Evans (1996) refere-se ao capital social, nas suas mais diversas acepções, ou seja: promover as redes existentes em territórios concretos de forma a se aglutinarem em torno de nós de dinamismo bem estabelecidos (sejam eles produtivos, associativos ou culturais). Considera ainda, que a noção de embeddedness (imergir em) é quem melhor define essa necessidade de articulação entre diversas organizações (nomeadamente o terceiro setor), as agências públicas e a implicação dos atores locais no futuro das respectivas comunidades e regiões. Tal como defende o autor, para se gerar esse tipo de sinergia, o Estado não pode ser posto de lado, mas também não deverá assumir um papel desmensurado e excessivamente centralizador, que impõe programas e projetos instituídos de cima para baixo. O Estado deve deter a elasticidade para imergir nos distintos contextos territoriais de maneira a propulsionar redes e plataformas de interconexões (capital social) que abarquem transversalmente os cidadãos, as associações e os agentes públicos. Mas, simultaneamente, deverá dotá-los das condições básicas para que esses detenham alguma capacidade de autonomia face a uma excessiva dependência do poder central.

Assim, a análise da confluência neste artigo assume a indissociabilidade do capital social, do empoderamento e da governança ambiental na promoção da sadia qualidade de vida. Busca-se aprofundar a discussão sobre a junção dos conceitos: capital social e empoderamento; empoderamento e participação da comunidade em políticas sociais e redes sociais, capital social e governança ambiental que, à luz dos artigos $225,5^{\circ}$, $1^{\circ}$, incisos III e $6^{\circ}$, da CF/1988, compõem o contexto da sadia qualidade de vida, dentro de uma gestão racional, que se justifica pela participação de todos no exercício do poder-dever compartilhado, em que a comunidade seja parte integrante da gestão pública participativa, para garantir o direito fundamental social à dignidade da pessoa humana, inerente à sadia qualidade de vida. Considerando-se essa perspectiva, optou-se por descrever os caminhos que levam o capital social, o empoderamento e a governança ambiental até a promoção da sadia qualidade de vida a partir 
da modelagem análise de caminhos ou path analysis. Contudo, inicialmente foram analisadas as relações entre os índices e indicadores de sadia qualidade de vida a partir da construção de uma matriz de correlação. Segundo Fávero et al. (2009), a matriz de correlação possibilita a análise simultânea da associação entre os conceitos a partir dos coeficientes de Pearson calculados por meio da expressão:

$$
r=\frac{\sum\left(x_{i}-\bar{x}\right)\left(y_{i}-\bar{y}\right)}{\sqrt{\sum\left(x_{i}-\bar{x}\right)^{2} * \sum\left(y_{i}-\bar{y}\right)^{2}}}
$$

A análise de caminhos ou Modelagem de Equações Estruturais é uma extensão da análise de regressão múltipla e se diferencia desta por permitir mais de uma variável dependente no modelo (MARUYAMA, 1998). A técnica inicia com a construção de um modelo conceitual capaz de descrever as relações observadas entre as variáveis. O propósito é estimar a intensidade das relações esquematizadas no modelo teórico, o que inclui o impacto direto de uma variável $X$ sobre outra variável Y e o impacto indireto de uma variável mediadora $Z$, posicionada entre X e Y. O modelo teórico que embasa a análise é representado por uma figura denominada diagrama de caminhos (FARIAS e SANTOS, 2000).

Um diagrama de caminhos ilustra as relações causais entre um conjunto de variáveis a partir de uma base teórica construída pelo pesquisador. É uma representação esquemática do modelo teórico que se pretende estudar. A Figura 1 representa o diagrama de caminhos proposto para analisar a confluência supracitada.

As variáveis observadas do modelo encontram-se nos retângulos: Índice de Empoderamento (IE), Índice de Capital Social (ICS), Índice de Governança Ambiental (IGA) e Índice de Sadia Qualidade de Vida (ISQV). Os círculos contêm as variáveis não observadas ou latentes, representando, aqui, os erros do modelo ou a variância não explicada. As setas apontam o caminho entre duas variáveis e ocorrem em dois sentidos: i) das variáveis exógenas para a variável endógena, representando o impacto do capital social, empoderamento e governança ambiental sobre a sadia qualidade de vida e ii) dos erros de medição para os indicadores reforçando o impacto do erro sobre os indicadores. $\mathrm{O}$ conjunto de setas permite identificar diferentes caminhos que levam à sadia qualidade de vida (confluência), no contexto estudado. Como todas as setas estão apontadas na mesma direção, isto é, no sentido da sadia qualidade de vida, o modelo proposto é recursivo, o que reforça a ideia de confluência adotada na hipótese da pesquisa.

A construção do Diagrama de Caminhos utiliza setas que representam as relações entre variáveis (SILVA, 2006). Setas curvilíneas descrevem a correlação

Figura 1. Diagrama de caminhos do modelo proposto

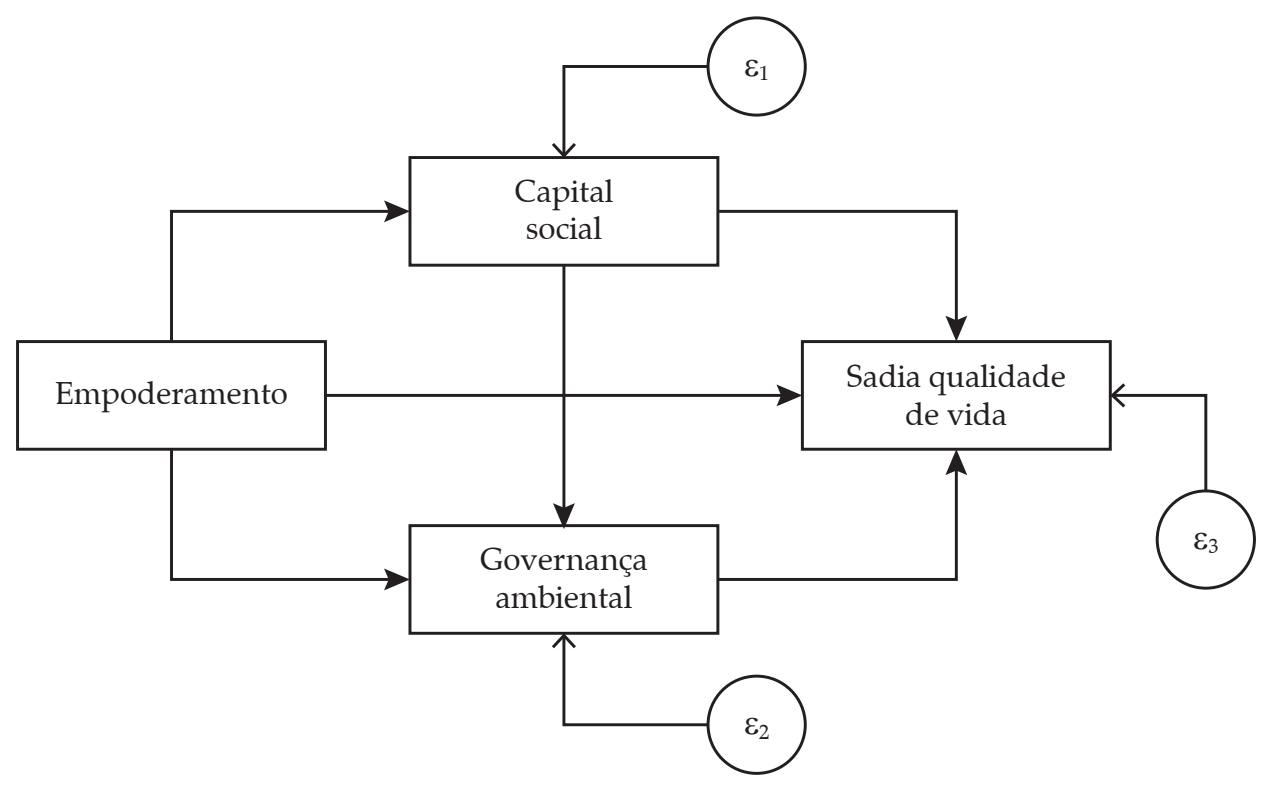

Fonte: Elaboração própria. 
entre variáveis. Setas retilíneas com um sentido descrevem o impacto unidirecional de variáveis independentes sobre variáveis dependentes e estão associadas a modelos recursivos. Setas retilíneas com dois sentidos descrevem relações recíprocas entre variáveis e estão associadas a modelos não recursivos.

Conforme Farias e Santos (2000), a análise de caminhos (path analysis) pode ser descrita matematicamente por meio de um conjunto de equações estruturais. Assim, após a construção do diagrama de caminhos, o passo seguinte foi a especificação do modelo em termos matemáticos, ou seja, a definição das equações que estabelecem a estrutura das relações entre as variáveis. As equações estruturais deverão fornecer os parâmetros do modelo que, por sua vez, informam quais variáveis são mais impactantes e apresentam relações significativas.

A tradução da Figura 1 em equações estruturais deve considerar que cada variável que possuir uma seta retilínea apontando para ela será uma variável dependente. As variáveis independentes da equação são aquelas das quais saem as setas retilíneas. Assim, o modelo proposto foi composto pelas seguintes equações estruturais:

$$
\begin{aligned}
& \mathrm{ICS}=\gamma \mathrm{IE}+e_{e} \\
& \mathrm{IGA}=\delta_{1} \mathrm{ICS}+\delta_{2} \mathrm{IE}+e_{g} \\
& \mathrm{ISQV}=\alpha_{1} \mathrm{ICS}+\alpha_{2} \mathrm{IE}+\alpha_{3} \mathrm{IGA}+e_{s q v}
\end{aligned}
$$

Sendo:

ICS = Índice de Capital Social

IE = Índice de Empoderamento;

IGA = Índice de Governança Ambiental;

ISQV = Índice de Sadia Qualidade de Vida;

$\gamma, \delta_{i}$ e $\alpha_{i}=$ parâmetros das regressões estimadas;

$e_{e}, e_{g}$ e $e_{s q \nu}=$ erros de medição nas regressões estimadas.

O método de estimação foi o de máxima verossimilhança. A escolha do tipo de matriz de dados consiste em definir se a matriz de entrada dos dados, a qual poderá ser a matriz de correlação (que utiliza dados padronizados) ou a matriz de covariância. Nesse estudo foi usada a matriz de correlação, pois permite comparações entre variáveis.

A principal vantagem da análise de caminhos é permitir um desdobramento das correlações entre as variáveis, de modo a tornar possível a percepção de relações de causalidade entre as mesmas. Nesse sentido, o modelo quantifica tanto os efeitos diretos quanto os efeitos indiretos das variáveis explicativas sobre a variável dependente. Os efeitos diretos e indiretos foram calculados a partir dos coeficientes estimados na regressão.

\section{Resultados e discussão}

A ideia central do artigo admite que não se pode pensar em sadia qualidade de vida nas comunidades rurais sem que haja uma causalidade entre esta e os conceitos de capital social, empoderamento e governança ambiental. Tal ideia foi analisada inicialmente a partir de uma argumentação com base teórica e empírica de modo a compreender o relacionamento entre os quatro elementos (Quadro 5). A argumentação teórica nem sempre é comprovada quando se dá o confronto com os resultados observados nas visitas às comunidades rurais (argumentação empírica).

A análise teórica confronta-se com a análise empírica em aspectos fundamentais como: elevado nível de empoderamento psicossocial, com pouca fluência para constituição de capital social. Baixa disponibilidade para a ação social, principalmente na formação de grupos e redes, que propiciam compromisso, confiança e confiabilidade, gerando cooperação mútua, necessárias à estrutura de governança ambiental. As normas e redes favorecem o engajamento cívico que, por sua vez, influi na participação dos atores no processo de reinvindicação e pressão por políticas públicas que melhorem as condições de vida. Contudo, nas comunidades o acesso aos indicadores sociais, motivados pelo projeto de desenvolvimento integrado Tabuleiro de Russas, tem melhorado a sadia qualidade de vida, mas não se verifica melhoria no índice de empoderamento e governança ambiental que signifique confluência direta entre os conceitos aqui analisados.

Os resultados na Tabela 1 reforçam a argumentação empírica. As correlações positivas e significativas entre capital social, empoderamento, governança ambiental e sadia qualidade de vida denotam que a presença de tais elementos nas comunidades fortalecem as relações e ações necessárias para resultados mais efetivos na criação de melhorias da sadia qualidade de vida. Uma análise desagregada da sadia qualidade de vida mostra, no entanto, que isoladamente muitos indicadores não apresentam relação significativa com capital social, empoderamento e governança ambiental. 


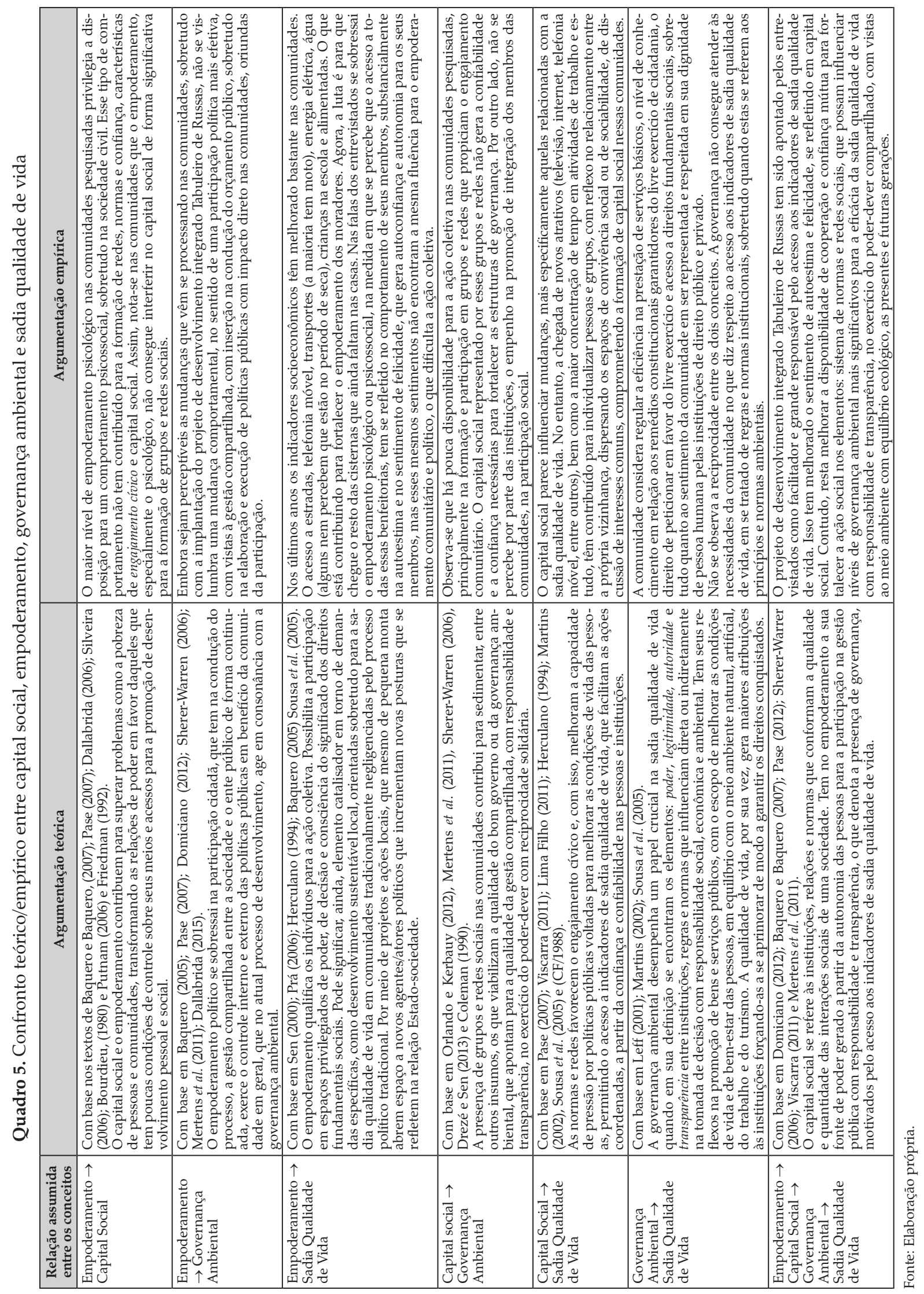


Tabela 1. Coeficientes de Correlação de Pearson entre capital social, empoderamento, governança ambiental e indicadores de sadia qualidade de vida nas comunidades visitadas

\begin{tabular}{lccc}
\hline & $\begin{array}{c}\text { Índice de } \\
\text { Capital Social }\end{array}$ & $\begin{array}{c}\text { Índice de } \\
\text { Empoderamento }\end{array}$ & $\begin{array}{c}\text { Índice de } \\
\text { Governança Ambiental }\end{array}$ \\
\hline Índice de Capital Social & - & - & - \\
Índice de Empoderamento & $0,637^{* *}$ & - & - \\
Índice de Governança & $0,726^{* *}$ & $0,558^{* *}$ & - \\
Índice de Sadia Qualidade de Vida & $0,584^{* *}$ & $0,546^{* *}$ & $0,425^{*}$ \\
Educação & $\mathbf{0 , 2 0 9}$ & $\mathbf{0 , 0 7 5}$ & $\mathbf{0 , 1 2 0}$ \\
Saúde & $\mathbf{0 , 2 3 4}$ & $\mathbf{0 , 2 4 3}$ & $\mathbf{0 , 0 0 6}$ \\
Alimentação & $\mathbf{0 , 2 6 5}$ & $\mathbf{0 , 0 4 4}$ & $\mathbf{0 , 0 5 2}$ \\
Trabalho & $\mathbf{0 , 0 6 8}$ & $\mathbf{0 , 0 5 6}$ & $\mathbf{0 , 1 3 6}$ \\
Moradia & $0,401^{*}$ & $0,467^{* *}$ & $0,417^{*}$ \\
Lazer & $0,507^{* *}$ & $0,369^{*}$ & $0,388^{*}$ \\
Segurança & $\mathbf{0 , 0 1 1}$ & $\mathbf{0 , 1 6 8}$ & $\mathbf{0 , 0 5 5}$ \\
Previdência Social & $0,474^{* *}$ & $0,482^{* *}$ & $0,466^{* *}$ \\
Proteção à maternidade e Infância & $0,438^{*}$ & $\mathbf{0 , 2 8 1}$ & $\mathbf{0 , 1 8 9}$ \\
Assistência aos Vulneráveis & $0,415^{*}$ & $0,518^{* *}$ & 0,268 \\
\hline
\end{tabular}

${ }^{*}$ Correlação significativa ao nível de significância 0,$05 ; * *$ Correlação significativa ao nível de significância 0,01 .

Fonte: Elaboração própria.

A correlação entre os quatro conceitos não significa a existência de uma relação de dependência, isto é, não se pode dizer, por exemplo, que sadia qualidade de vida depende dos conceitos de capital social, empoderamento e governança ambiental analisados na pesquisa ou vice-versa. Assim, no sentido de melhor compreender a estrutura das relações discutidas, optou-se pela Análise de Caminhos (Path Analysis).
Como mencionado anteriormente, a Análise de Caminhos permite a construção de um diagrama que pode ser interpretado como um resumo de um conjunto de hipóteses formuladas a partir de base teórica bem fundamentada. Nesse sentido, as relações conceituais discutidas no Quadro 5 e as relações verificadas na Tabela 1 podem ser sintetizadas na Figura 2.

Figura 2. Diagramas de caminho para as relações entre capital social, empoderamento, governança e sadia qualidade de vida (todos os coeficientes dos caminhos são padronizados)

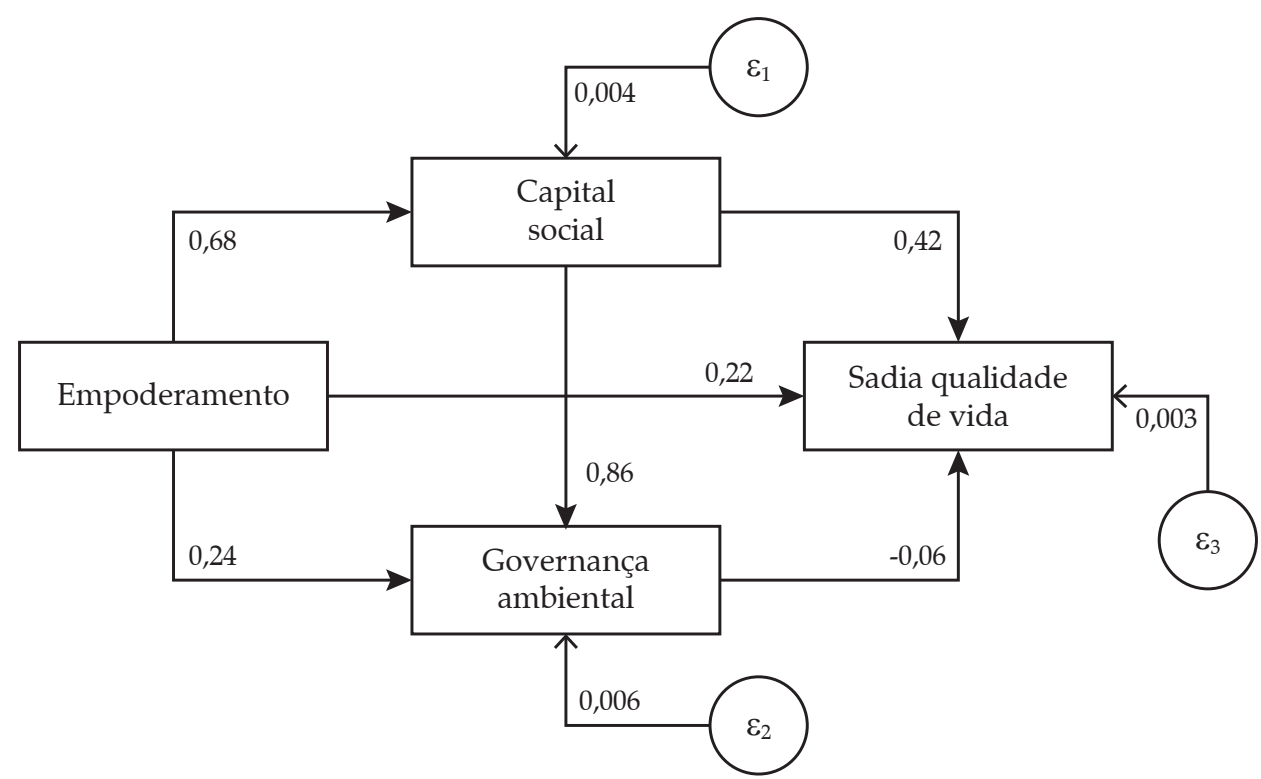

Fonte: Elaboração própria. 
O conjunto de setas permite identificar diferentes caminhos que levam à sadia qualidade de vida (confluência), no contexto estudado. Os valores próximos às setas são os coeficientes de regressão padronizados ou coeficientes path, correspondentes às equações estruturais descritas na metodologia.

A partir da Tabela 2 é possível visualizar a significância de cada coeficiente estimado. Nota-se que o empoderamento tem efeito direto significativo sobre o capital social nas comunidades. No entanto, não influencia diretamente a governança ambiental nem a sadia qualidade de vida. Por outro lado, o capital social atua direta e significativamente sobre esses dois elementos. Com base nas informações colhidas durante a pesquisa de campo nota-se que a existência de um elevado nível de empoderamento psicológico não conseguiu elevar os níveis de empoderamento político e social, o que acabou por prejudicar os indicadores de grupos e redes sociais. Isso se deve à forma como a participação social leva ao engajamento comunitário, impulsionando o compromisso, confiança e confiabilidade, formadores de cooperação mútua que, nas comunidades pesquisadas, assim como já percebido por Baquero e Baquero (2007), Putnam (1997) e os intelectuais americanos, tem sido assistido o recrudescimento do individualismo ou comportamento individualista, principalmente após o advento da globalização e o consequente acesso a indicadores de melhores condições de vida.
Esse comportamento tende a chamar atenção para os indicadores de governança ambiental. $\mathrm{O}$ estado democrático de direito requer de seus cidadãos, conhecimento e participação. Isso se ressente nas comunidades pesquisadas: há certa inércia, falta de interesse maior por parte de seus membros para participar da condução e encaminhamento das questões e políticas públicas que possam contribuir para que o local possa ser preservado, sem, contudo, impedir ou inviabilizar o acesso à sadia qualidade de vida com responsabilidade compartilhada, tendo nos elementos poder, legitimidade, autoridade e transparência a marca do pensar global e agir local na promoção do desenvolvimento/ envolvimento.

Em um sistema linear, o efeito causal total de uma variável $i$ na variável $j$ é a soma dos valores de todos os caminhos de $i$ a $j$. Ao longo desses caminhos, observa-se que existem efeitos diretos e indiretos. Os coeficientes betas padronizados representam os efeitos diretos das variáveis independentes sobre as variáveis endógenas (dependentes) quando o caminho não é interrompido por uma variável mediadora (aquela posicionada entre duas variáveis). No caso da existência de variáveis mediadoras o produto dos coeficientes ao longo do caminho reflete o peso desse caminho.

Assim, no caso das variáveis Sadia Qualidade de Vida (dependente) e Capital Social (independente), o efeito indireto do capital social sobre a sadia qualidade de vida é obtido multiplicando os coeficientes de para

Tabela 2. Estimação do modelo de equações estruturais proposto no diagrama de caminhos

\begin{tabular}{|c|c|c|c|c|}
\hline & $\begin{array}{l}\text { Coeficiente de regressão padro- } \\
\text { nizado }\end{array}$ & Erro Padrão & $\mathbf{Z}$ & $P>z$ \\
\hline \multicolumn{5}{|c|}{ Eq. Estrutural: ICS $=\alpha_{1}+\beta_{1} \mathrm{IE}+\varepsilon_{1}$} \\
\hline IE & 0,681 & 0,148 & 4,60 & 0,000 \\
\hline Constante & 0,115 & 0,110 & 1,05 & 0,295 \\
\hline \multicolumn{5}{|c|}{ Eq. Estrutural: IGA $=\alpha_{2}+\beta_{2} \mathrm{IE}+\beta_{3} \mathrm{ICS}+\varepsilon_{2}$} \\
\hline ICS & 0,862 & 0,218 & 3,96 & 0,000 \\
\hline IE & 0,238 & 0,233 & 1,02 & 0,307 \\
\hline Constante & $-0,152$ & 0,135 & $-1,13$ & 0,260 \\
\hline \multicolumn{5}{|c|}{ Eq. Estrutural: ISQV $=\alpha_{3}+\beta_{4} \mathrm{IE}+\beta_{5} \mathrm{ICS}+\beta_{6} \mathrm{IGA}+\varepsilon_{3}$} \\
\hline ICS & 0,420 & 0,204 & 2,05 & 0,040 \\
\hline IGA & $-0,060$ & 0,138 & $-0,44$ & 0,663 \\
\hline IE & 0,219 & 0,181 & 1,21 & 0,226 \\
\hline Constante & 0,264 & 0,106 & 2,50 & 0,012 \\
\hline
\end{tabular}

Teste do qui-quadrado da razão de verossimilhança*: qui quadrado $(0)=0,000$

Nota: ${ }^{*}$ ) Vários critérios podem ser usados para avaliar o ajuste do modelo (goodfitness measures). O teste do qui-quadrado da razão de verossimilhança é um deles. Segundo Garson (2008), o valor zero na estatística qui-quadrado indica um modelo saturado, ou seja, perfeitamente explicativo, embora trivial modelo (com todas as setas possíveis).

Fonte: Elaboração própria. 
cada caminho indireto de capital social até sadia qualidade de vida. No caso: Capital Social $\rightarrow$ Governança Ambiental $\rightarrow$ Sadia Qualidade de Vida $(0,862 *-0,06=$ -0,052). O efeito direto é o coeficiente estimado na equação Capital Social $\rightarrow$ Sadia Qualidade de Vida $(0,420)$. O efeito total do capital social sobre a sadia qualidade de vida é a soma dos efeitos direto e indireto $(0,368)$.

$\mathrm{Na}$ Tabela 3 constam os efeitos diretos e indiretos de cada variável independente nos modelos de equações estruturais estimados. O capital social mostrou ter um importante impacto direto na governança ambiental e na sadia qualidade de vida, inclusive maior que o empoderamento. No entanto, direcionando a atenção para o efeito total, e para a equação da Sadia Qualidade de Vida, nota-se que Capital Social e Governança Ambiental não contribuem para a Sadia Qualidade de Vida a um nível de significância de $5 \%$, enquanto os desdobramentos do empoderamento fazem com que esta variável seja a de maior importância na promoção da sadia qualidade de vida nestas comunidades.

Isso demonstra, na prática, que mesmo tendo sido corroborada a hipótese desse estudo, resta investir em todos os conceitos aqui trabalhados para que fortaleça a confluência, de forma que as fragilidades e vulnerabilidades de um se convertam em força e poder para compensar ou ser compensado nessa relação que possam, assim, seguir o seu curso rumo à sadia qualidade de vida com equidade e justiça social.

\section{Considerações finais}

A análise de caminhos mostrou que existe uma confluência dos conceitos capital social, empoderamento e governança ambiental em direção à sadia qualidade de vida nas comunidades rurais visitadas. Capital social e empoderamento atuam direta e indiretamente no processo, mas cabe ao capital social a promoção das mudanças significativas.

O empoderamento ganha destaque, também, devido a sua capacidade de influenciar o capital social. No entanto, no que se refere à governança ambiental, o estudo permite concluir que as condições atuais verificadas nas comunidades não permitem que a mesma exerça seu papel esperado na promoção da sadia qualidade de vida. Ainda como uma conclusão da análise de caminhos, ressalta-se que o capital social, ao contrário do empoderamento, é um fator determinante da governança ambiental sendo, portanto, um indicador a ser trabalhado no novo contexto institucional que se desenha nas áreas rurais.

As conclusões foram elaboradas a partir de uma análise empírica que, quando confrontada com o modelo teórico, mostrou que condições específicas das comunidades rurais podem provocar divergências conceituais. Conforme aceito na literatura, o capital social nas comunidades depende do empoderamento para melhorar as condições de vida, na perspectiva dos direitos fundamentais sociais do art. $6^{\circ}$, em consonância com os artigos 225, 1ํㅡ, III e 5o da CF/1988. Essa relação foi confirmada na pesquisa, haja vista que pesquisas empíricas confirmam que a presença de capital social contribui para fortalecer a inserção de indivíduos engajados nas ações sociais de maneira mais efetiva e igualitária. Além disso, para Putnam (1997) e Fukuyama (1995), a qualidade da governança ambiental nas comunidades depende de capital social. A pesquisa corroborou essa ideia ressaltando que a cooperação e a confiança social requerem uma prática reiterada de costumes e normas que facilitam a ação social em detrimento da ação psicossocial, que no caso das comunidades tem se refletido

Tabela 3. Efeitos diretos, indiretos e totais estimados nas equações estruturais estimadas na pesquisa

\begin{tabular}{llccc}
\hline \multicolumn{1}{c}{ Variável impactada } & Variável impactante & Efeito direto & Efeito indireto & Efeito total \\
\hline Capital Social & Empoderamento & $0,681^{*}$ & 0,000 & $0,681^{*}$ \\
\hline \multirow{2}{*}{ Governança } & Empoderamento & 0,238 & $0,587^{*}$ & $0,825^{*}$ \\
& Capital Social & $0,862^{*}$ & 0,000 & $0,862^{*}$ \\
\hline \multirow{2}{*}{ Sadia Qualidade de Vida } & Empoderamento & 0,219 & $0,237^{* * *}$ & $0,456^{*}$ \\
& Capital Social & $0,420^{* *}$ & $-0,052^{*}$ & $0,368^{* * *}$ \\
& Governança & $-0,060$ & 0,000 & $-0,060$ \\
\hline
\end{tabular}

Nota: Significativo $\mathrm{a}^{*}=0,01, * *=0,05 \mathrm{e}^{* * *}=0,1$.

Fonte: Elaboração própria a partir da análise de equações estruturais. 
no descontentamento e recuo nos interesses de assuntos da esfera política e social.

Contudo, o empoderamento, elemento tido como propulsor do capital social e de governança ambiental, mostrou-se inapto a contribuir para melhores índices de governança ambiental nas comunidades. Segundo Baquero e Baquero (2007), em anos recentes tem se verificado uma tendência crescente ao individualismo, como também as noções individuais de progresso self made man (homem que se faz por si). Apesar do aumento no nível de autoconfiança, isso não tem conseguido se converter em benefícios ou compensação para a sadia qualidade de vida, no que se refere aos conceitos de empoderamento e governança ambiental.

Para Pase (2012) e Mertens et al. (2011), o desenvolvimento das comunidades rurais passa pelo acesso a indicadores de sadia qualidade de vida, motivados pela participação da sociedade no planejamento, elaboração e execução de políticas públicas viabilizadas pelo capital social, a partir do empoderamento dos indivíduos que incide em governança ambiental, elevando, assim, o nível de acesso aos direitos fundamentais

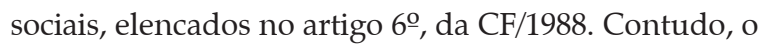
que se sobressai nas comunidades é a pouca disposição para a formação de grupos e redes sociais, elementos facilitadores de confiança e confiabilidade nas pessoas e instituições de modo geral.

Por fim, acredita-se que o presente estudo tem possibilidades reais de contribuir para a elaboração e execução de políticas públicas e programas voltados para a participação da comunidade no desenvolvimento/envolvimento melhorando, assim, o acesso a direitos sociais com a participação responsável e solidária para alcançar a sadia qualidade de vida, em um meio ambiente com equilíbrio ecológico, às presentes e futuras gerações.

\section{Referências}

AMARAL, C. E. R. Tutela dos direitos fundamentais dos grupos sociais vulneráveis competente à defensoria pública. Jus Brasil, 2011.

ASHLEY, C. e MAXWELL, S. Rethinking rural development. Development policy review, v. 19, n. 4, p. 395-425, 2001.

AVELINE, P. V. Segurança Pública como direito fundamental. Dissertação 187fls. (Mestrado em Direito).
Pontifícia Universidade Católica do Rio Grande do Sul. Porto Alegre, 2009.

BAQUERO, R. A. V. Empoderamento: questões conceituais e metodológicas. Revista Debates, v. 1, p. $69-84,2005$.

BAQUERO, M. e BAQUERO, R. Trazendo o cidadão para a arena pública: capital social e empoderamento na produção de democracia social na América Latina. Redes, Santa Cruz do Sul, v. 12, n. 1, p. 125-150, jan./abr. 2007.

BELLEN, H. M. V. Indicadores de sustentabilidade um levantamento dos principais sistemas de avaliação. Cad. EBAPE.BR, v. 2, n. 1, Rio de Janeiro, mar. 2004

BOBBIO, N. A era dos direitos. 11. ed. São Paulo: Paz Terra e Política: LTr, 2004.

BOURDIEU, P. Le capital social: notes provisoires. In: Actes de la Recherche em Sciences Sociales, n. 31. Paris: France, jan. 1980.

CAPRA, F. O ponto de mutação. Tradução de Alvaro Cabral. 28. ed. São Paulo: Cultrix, 2007.

CARMO, R. M. Capital social e policentrismo: para uma análise reflexiva das políticas públicas. In: COLÓQUIO IBÉRICO DE ESTUDOS RURALES, Coimbra, Portugal, 23-25 out. 2008.

CARVALHO, S. R. Os múltiplos sentidos da categoria empowerment no projeto de promoção à saúde. Cad. Saúde Pública, Rio de Janeiro, v. 20, n. 4, p. 1088-1095, 2004.

CARVALHO, O. F. O direito fundamental à alimentação e sua proteção jurídico-internacional. Revista de Direito Público, Londrina, v. 7, n. 2, p. 181-224, maio/ago. 2012.

COLEMAN, J. S. Foundations of Social Theory. Cambridge, Massachusetts: Harvard University Press, 1990.

CONSTITUIÇÃO DA REPÚBLICA FEDERATIVA DO BRASIL. Brasília, DF: Senado Federal, 1988.

COSTA, R. J. Z., COSTA, F. M. e NASCIMENTO, V. A. Construção social de indicadores ambientais para a gestão de bacias hidrográficas. In: CONGRESSO IBEROAMERICANO SOBRE DESARROLLO Y AMBIENTE, V CISDA, Santa Fé, Argentina, 12 a 14 de setembro de 2011.

CRUZ, N. F. e MARQUES, R. C. Índice de governança municipal: utilidade e exequibilidade. In: CONGRESSO NACIONAL DE ADMINISTRAÇÃO PÚBLICA, VIII, Instituto Nacional de Administração - ina, 21 e 22 de nov. 2011.

DALLABRIDA, V. R. Governança territorial: do debate teórico à avaliação da sua prática. Análise Social, v. L( $\left.2^{\circ}\right)$, n. 215, p. 304-328, 2015. 

no Ceará

DALLABRIDA, V. R. A dimensão intangível do desenvolvimento: algumas reflexões preliminares. In: BAQUERO, M. e CREMONESE, D. (Orgs.). Capital Social: teoria e prática. Ijuí: maio, 2006. Disponível em: $<$ www.plataformademocratica.org/htm $>$. Acesso em: 20 maio 2014.

DE JANVRY, A., SADOULET, E. e MURGAI, R. Rural development and rural policy. Handbook of agricultural economics, v. 2, p. 1593-1658, 2002.

DECRETO n. 6.949 - promulga Convenção Internacional 2007 sobre os Direitos das Pessoas com Deficiência, Brasília, 26 ago. 2009.

DIAS, D. S. O direito à moradia digna e a eficácia dos Direitos fundamentais sociais. Revista Eletrônica do CEAF, Porto Alegre-RS, Ministério Público do Estado do RS, v. 1, n. 1, out. 2011/jan. 2012

DIENER, E. e SUH, E. Measuring quality of life: Economic, social, and subjective indicators. Social Indicators Research, v. 40, n. 1-2, p. 189-216, 1997.

DOMICIANO, C. S. O capital social e a educação ambiental como elementos catalizadores de empoderamento em comunidades. Ver. Eletrônica do mestrado em Educ. Ambiental, v. 28, jan./jun. 2012.

DRÈZE, J. e SEN, A. Glória incerta: a Índia e suas contradições. Tradução de Ricardo Doninelli Mendes e Leila Coutinho. São Paulo: Companhia das Letras, 2015.

EMENDA CONSTITUCIONAL № 064, 2010. Altera o artigo $6^{\mathrm{O}}$ para introduzir a alimentação como direito social. Brasília, 05.02.2010.

EVANS, P. Government action, social capital and development: reviewing the evidence on synergy. World Development, v. 24, n. 6, 1996.

FAO - FOOD AND AGRICULTURE ORGANIZATION OF THE UNITED NATIONS (FAO/ONU). Diretrizes voluntárias em apoio à realização progressiva do direito à alimentação adequada no contexto da segurança alimentar nacional. Roma: FAO, 2004.

FARIAS, S. A. e SANTOS, R. C. Modelagem de equações estruturais e satisfação do consumidor: uma investigação teórica e prática. Rev. Adm. Contemp., Curitiba, v. 4, n. 3, dez. 2000.

FÁVERO, L. P. et al. Análise da dados: modelagem multivariada para tomada de decisões. Rio de Janeiro: Elsevier, 2009.

FELCE, D. e PERRY, J. Quality of life: its definition and measurement. Research in Developmental Disabilities, v. 16, n. 1, p. 51-74, 1995.
FIORILLO, C. A. P. Curso de direito ambiental brasileiro. 6. ed. (ampl.) São Paulo: Saraiva, 2005.

FONSECA e BURSZTYN. A banalização da sustentabilidade: reflexões sobre governança ambiental em escala local. Sociedade e Estado, Brasília, v. 24, n. 1, p. 17-46, jan./abr. 2009.

FONTANELLA, B. J. B. et al. Amostragem em pesquisas qualitativas: proposta de procedimentos para constatar saturação teórica [Sampling in qualitative research: a proposal for procedures to detect theoretical saturation]. Caderno de Saúde Pública, v. 27, p. 389-394, 2011.

FREIRE, P. Educação como prática para a liberdade. 17. ed. Rio de Janeiro: Paz e Terra, 1986.

. Pedagogia do oprimido. 17. ed. Rio de Janeiro: Paz e Terra, 1988.

FRIEDMAN, J. Empowerment: the politics of alternative development. Cambridge: Blackwell Publishers, 1992.

FUKUYAMA, F. Trust: the social virtues and the creation of prosperity. New York: The Free Press, 1995.

GALLO, G. N. Direito à moradia: direito humano fundamental. Disponível em: <www.conpedi.org.br/ manaus/arquivos/anais/bh/gabriela_neves_gallo.pdf $>$. Acesso em: 29 maio 2014.

GARSON, G. D. Path analysis from statnotes: topics in multivariate analysis. Retrieved, v. 9, n. 5, p. 2009, 2008.

GOBO G. Sampling, representativeness and generalizability. In: SEALE, C. et al. (Eds.). Qualitative research practice. London/Thousand Oaks/New Delhi: Sage Publications, 2007, p. 405-426.

GOHN, M. G. Empoderamento e participação da comunidade em políticas sociais. Saúde e Sociedade, v. 13 , n. 2, p. 20-31, maio/ago. 2004

GOMES, G. A. O. e PAPALÉO, A. L. Empowerment, direitos humanos e qualidade de vida na escola. Disponível em: < http://www.fef.unicamp.br/departamentos/deafa/ qvaf/livros/alimen_saudavel_ql_af/escolares/escolares_ cap12.pdf>. Acesso em: 5 maio 2015.

GRANOVETTER, M. Economic action and social structure: the problem of embeddedness. The American Journal of Sociology, v. 91, n. 3, p. 481-510, 1985.

GRINDLE, M. S. Good enough governance: poverty reduction and reform in developing countries. Governance, v. 17, n. 4, p. 525-548, 2004.

HARRIS, J. Public action and the dialectics of decentralisation: against the myth of social capital and the missing link in development. Social Scientist, v. 29, p. 25-40, 2001. 
HERCULANO, S. C. A qualidade de vida e seus indicadores. In: HERCULANO, S. et al. (Org.). Qualidade de vida e riscos ambientais. Niterói: Eduff, 1994.

HERMANY, R. e COSTA, D. L. A necessária superação do modelo representativo hegemônico na construção do empoderamento social local. Revista do Direito, Santa Cruz do Sul, v. 32, n. 2, p. 78-91, jul./dez. 2009.

HORVATH JÚNIOR, M. Os direitos fundamentais e a seguridade social. Âmbito Jurídico, Rio Grande, IX, n. 31, jun. 2006.

JOHANNPETER, M. H. P. O que é capital social? ONGs parceiros voluntários/RS. Disponível em: <www. parceirosvoluntarios.org.br > . Acesso em: 12 maio 2012. JOSÉ SALES (Org.). PDR baixo jaguaribe: plano de desenvolvimento regional. Edição PDR. Secretária do Desenvolvimento Local e Regional / SDLR, 2000.

KAUFMANN, D., KRAAY, A. e MASTRUZZI, M. Governance Matters VIII: aggregate, and individual governance indicators for 1996-2008, World Bank Policy Research Working Paper n. 4978, Washington, DC. 2009.

KIM, et al. Toward participatory and transparent governance: report in the Sixth Global Forum on Reinventing Government, Public Administration Review, v. 65, n. 6, p. 646-654, 2005.

KOPPENJAN, et al. Contexts, hybrids and network governance: a comparison of three case-studies in infrastructure governance. In: BRANDSEN, T. e HOLZER, M. (Eds.). The future of governance. Newark, NJ: NCPP, 2010, p. 301-325.

LEFF, E. Saber ambiental: sustentabilidade, racionalidade, complexidade, poder. Tradução de Lúcia Mathilde Endlich Ortth. Petrópolis: Vozes, 2001.

LIMA FILHO. Capital social e desenvolvimento sustentável: a experiência de Campo do Brito (SE). Documentos Técnico-Científico, v. 42, n. 1, jan/mar. 2011.

MACKINNON, D. Rural governance and local involvement: assessing state - community relations in the Scottish Highlands. Journal of Rural Studies, v. 18, n. 3, p. 307-324, 2002.

MARCHI, W. R. A. A segurança pública como direito fundamental e a reorganização da polícia civil paulista. Dissertação (Mestrado em Direito) - Centro Universitário FIEO-UNIFIEO. Osasco, 2010.

MARTINS, C. H. B. Pobreza, meio ambiente e qualidade de vida: indicadores para o desenvolvimento humano sustentável. Indic. Econ. FEE, Porto Alegre, v. 30, n. 3, p. 171-188, dez. 2002.
MARUYAMA, G. M. Basics of structural equation modeling. London: Sage Publications, 1998.

MCFARLAND, A. Neopluralismo. Annual Review of Political Science, v. 10, p. 45-66, 2007.

MERTENS et al. Redes sociais, capital social e governança ambiental no território Portal da Amazônia. ActaAmazonica, v. 41, n. 4, p. 481-492, 2011.

MILANI, C. Teorias do capital social e desenvolvimento local: lições a partir da experiência de Pintadas (Bahia, Brasil). In: CONFERÊNCIA REGIONAL ISTR-LAC, IV. São José, Costa Rica, 08 a 10 de out. 2003.

MIRAGLIA, L. M. M. O direito do trabalho como instrument de efetivação da dignidade social da pessoa humana no capitalismo. Rev. Trib. Reg., Belo Horizonte, v. 49, n. 79, p. 149-162, jan./jun. 2009.

MONTEIRO, J. R. Direito fundamental: direito à alimentação ainda deve ser efetivado. São Paulo: Consultor Jurídico, 23 mar. 2011.

MORAES FILHO, E. Introdução ao direito do trabalho. São Paulo: LTr, 2010.

MOREIRA, J. C. B. Temas de direito processual. São Paulo: Saraiva, 1977.

MORIN, E. A via para um futuro da humanidade. Tradução de Edgard de Assis Carvalho e Mariza Perassi Bosco. Rio de Janeiro: Bertrand Brasil, 2013.

NARAYAN, D. Empoderamiento y redución de la pobreza. Libro de consulta. Bogotá: Banco Mundial/Alfa Omega, 2002.

NARDO, M. et al. Handbook on Constructing Composite Indicators: Methodology and User Guide, OECD Statistics Working Papers, 2005/03, OECD Publishing. http://dx.doi.org/10.1787/533411815016. 2005.

OLIVEIRA, M, B. O direito ao lazer na formação do homem social. Âmbito Jurídico, Rio Grande, v. XIII, n. 76, maio 2010.

ONU - Organização das Nações Unidas. Conferência mundial Sobre direitos humanos, Viena, 1993.

ORLANDO, R. S. e KERBAUY, M. T. M. Perspectivas teóricas para análises de questões ambientais: capital social e governança, In: ENCONTRO NACIONAL DE ANPPAS, VI, Bélem - PA - Brasil, 18 a 21 de set. 2012

OSTRON, E. Invest ing in capital, institutions, and incentives. In: CLAUGUE, C. (Ed.). Institutions and Economic Development: Growth and Governance in Less Developed and Post-Socialist Countries. Maryland: Johns Hopkins University, 1997. 

no Ceará

PASE, H. L. Capital social e desenvolvimento: uma abordagem cultural das desigualdades regionais. Redes (Santa Cruz do Sul), v. 11.2, p. 135-153, 2007.

Capital social e qualidade de vida. Revista Debates, Porto Alegre, v. 6, n. 1, p. 35-59, jan./abr. 2012.

PERREZ HARO, E. Participación social y empoderamento para la gestión del desarollo. Relatório apresentado para a Oficina Internacional sobre Participação e Empoderamento para um Desenvolvimento Inclusivo. Peru, jun. 2004.

PRÁ, J. R. Políticas públicas, direitos humanos e capital social. In: BAQUERO, M. e CREMONESE, D. (Orgs.). Capital social: teoria e prática. Ijui: UNIJUÍ, maio 2006, p. 176-192.

PRETTY, J. e WARD, H. Social capital and the environment. World Development, v. 29, p. 209-227, 2001.

PUTNAM, R. D. Comunidade e democracia: a experiência da Itália moderna. 5. ed. Rio de Janeiro: FGV, 2006.

. Democracies in flux. The evolucion of social capital in contemporary societies. New York: Oxford University Press, 2002, p. 3-21.

Democracy in America at century's end. In: HADENIUS, A. Democracy's victory and crisis. Cambridge: Cambridge University Press, 1997.

. El declive del capital social: un studio internacional sobre las sociedades y el sentido comunitario. Barcelona: Galaxia Gutemberg, 2003.

RICH, R. C. et al. Citizen participation and empowerment. American Journal of Community Psicology, v. 23, n. 5, p. 657-76, out. 1995.

RODRIGUES, M. I. V. Os princípios da governança e as políticas públicas para o desenvolvimento sustentável. 213fls. Tese (Doutorado) - Universidade Federal do Ceará, Centro de Ciências, Pró-Reitoria de Pesquisa e PósGraduação em Desenvolvimento e Meio Ambiente, Fortaleza, 2014.

ROMANO, J. e ANTUNES, M. Empoderamento: enfrentemos primeiro a questão do poder para combater juntos a pobreza. Documento de apoio apresentado no International Workshop Empowerment and Right Based Approach in Fighting Poverty Together. Rio de Janeiro, Brasil, 4 set. 2002.

SARLET, I. W. A eficácia dos direitos fundamentais 1998; PIOVESAN, Flávia. Constituição e transformação social: a eficácia das normas constitucionais programáticas e a concretização dos direitos e garantias fundamentais: In: Rev. da PGE/SP, 1998.

SCHERER-WARREN, I. Das mobilizações às redes de movimentos sociais. Sociedade E Estado, Brasília, v. 21, n. 1, p. 109-130, jan./abr. 2006

SCHIAVO, M. R. e MOREIRA, E. N. Glosário social. Rio de Janeiro: Comunicarte, 2005.

SEN, A. Sobre ética e economia. 8. ed. Tradução de Laura Teixeira Mota. São Paulo: Companhia das Letras, 1999.

Desenvolvimento como liberdade. São Paulo: Companhia das Letras, 2000.

SILVA, J. S. F. Modelagem de equações estruturais: apresentação de uma metodologia. Dissertação (Mestrado em Engenharia de Produção) - Universidade Federal do Rio Grande do Sul, Rio Grande do Sul, 2006.

SILVEIRA, A. F. O empoderamento e a constituição de capital social, entre a juventude. In: BAQUERO, M. e CREMONESE, D. (Orgs.). Capital social: teoria e prática. Ijuí: maio 2006. Disponível em: <www. plataformademocratica.org $/ \mathrm{htm}>$. Acesso em: 20 maio 2014.

SOARES, D. A. O direito fundamental à educação e a teoria do não retrocesso social. Revista de Informação Legislativa, Brasília, ano 47, n. 186, abr.jun. 2010.

SOUSA, M. C. et al. Sustentabilidade da agricultura familiar em assentamentos da reforma agrária no Rio Grande do Norte. Rev. Econômica do Nordeste, Fortaleza, v. 36, n. 1, p. 96-120, jan./mar, 2005.

TAVARES, M. L. Previdência e assistência social: legitimação e fundamentação constitucional brasileira. Rio de Janeiro: Lumen Juris, 2003.

UMANS, L. e ARCE, A. Fixing rural development cooperation? Not in situations involving blurring and fluidity. Journal of Rural Studies, v. 34, p. 337-344, 2014.

VASILEVSKA, L. Rural development and regional policy: Conceptual framework. Facta universitatis-series: Architecture and Civil Engineering, v. 8, n. 3, p. 353-359, 2010.

VISCARRA, S. P. Desenvolvimento econômico, capital social e qualidade de vida em Porto Alegre/RS, 2011.

WALLERSTEIN e BERNSTEIN. Introduction to community empowerment, participation, educacion, end health. Health Educacion Quarterly: Special Issue, 1994.

ZANK et al. Empoderamento de comunidades rurais e o estabelecimento de uma reserva de desenvolvimento sustentável: estudo de caso nas áreas da Ribanceira. Biodiversidade Brasileira, Ibituba-SC, v. 2, n. 2, p. 33-49, 2012. 